OPEN ACCESS

Edited by:

Masataka Sata,

Tokushima University, Japan

Reviewed by:

Alessandro ladanza

Università degli Studi di Siena, Italy Antonio Francesco Corno,

University of Leicester, United Kingdom

*Correspondence: Jing Wang

jingwang2004@hust.edu.cn

Specialty section: This article was submitted to

Vascular Physiology,

a section of the journal

Frontiers in Physiology

Received: 30 October 2018 Accepted: 20 December 2018

Published: 30 January 2019

Citation:

Liu T, Xie M, Lv Q, Li Y, Fang L, Zhang L, Deng W and Wang J (2019) Bicuspid Aortic Valve: An Update in Morphology, Genetics, Biomarker, Complications, Imaging Diagnosis and Treatment.

Front. Physiol. 9:1921. doi: 10.3389/fphys.2018.01921

\section{Bicuspid Aortic Valve: An Update in Morphology, Genetics, Biomarker, Complications, Imaging Diagnosis and Treatment}

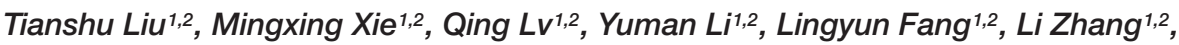 \\ Wenhui Deng ${ }^{1,2}$ and Jing Wang ${ }^{1,2 *}$
}

${ }^{1}$ Department of Ultrasound, Union Hospital, Tongji Medical College, Huazhong University of Science and Technology, Wuhan, China, ${ }^{2}$ Hubei Province Key Laboratory of Molecular Imaging, Wuhan, China

The bicuspid aortic valve, a kind of heart disease that comes from parents, has been paid attention around the world. Although most bicuspid aortic valve (BAV) patients will suffer from some complications including aortic stenosis, aortic regurgitation, endocarditis, and heart dysfunction in the late stage of the disease, there is none symptom in the childhood, which restrains us to diagnose and treatment in the onset phase of BAV. Hemodynamic abnormalities induced by the malformations of the valves in BAV patients for a long time will cause BAV-associated aortopathy: including progress aortic dilation, aneurysm, dissection and rupture, cardiac cyst and even sudden death. At present, preventive surgical intervention is the only effective method used in this situation and the diameter of the aorta is the primary reference criterion for surgery. And the treatment effects are always not satisfactory for patients and clinicians. Therefore, we need more methods to evaluate the progression of BAV and the surgery value and the appropriate intervention time by combining basic research with clinical treatment. In this review, advances in morphology, genetic, biomarkers, diagnosis and treatments are summarized, which expects to provide an update about BAV. It is our supreme expectations to provide some evidences for BAV early screening and diagnosis, and in our opinion, personalized surgical strategy is the trend of future BAV treatment.

Keywords: BAV, morphology, genetics, biomarker, aortopathy, valvulopathy

\section{INTRODUCTION}

Bicuspid aortic valve (BAV) disease has the characteristic of heredity with variable genetic penetrance. And $0.5-2 \%$ of the population worldwide have the possibility to be attacked by this disease, which 75\% of them are male (Dargis et al., 2016; Longobardo et al., 2016). Initially, most children with BAV disease are asymptomatic and not aware of its presence, resulting in complications which are presented in adulthood. Accurate diagnosis at early stage and effective intervention are essential to prevent various complications. Nature history of patients with surgery is not same as normal ones, therefore continued surveillance and personalized surgical therapy are required. Although a series of studies have introduced some aspects of BAV including etiology, 
rheology, morphology and genetics, questions are still unanswered (Masri et al., 2017b). This review provides a brief introduction of morphology characteristics, recent advances on genetic and biomarkers, and update in imaging diagnosis and recommendations for the treatment of BAV disease.

\section{MORPHOLOGY: DIFFERENT CLASSIFICATION ENDOW DIFFERENT EFFECTS}

The typical structure of the aortic valve had three semilunar leaflets in shape. Due to the fusion of two cusps out of three, BAV usually included two unequal cusps and a central raphe.

From a surgical point of view, Sievers classification system was used widely in Figure 1A (Sievers and Schmidtke, 2007). Based on number of raphes, three categories of BAV are presented in patients including type 0 (no raphe in the valve), type 1 (only one raphe in the valve) and type 2 (two raphes in the valve). And the most common type is type 1, which accounting for about $90 \%$ of the patients (Sievers et al., 2014). On the basis of the raphe position with coronary sinuses, types 1 and 2 were classified as left $(\mathrm{L})$, right $(\mathrm{R})$ and none $(\mathrm{N})$ type. The right and left coronary leaflet (RL) were most common accounted for about $80 \%$, the right and non-coronary leaflet (RN) was about $17 \%$ and left and non-coronary leaflet (LN) was $2 \%$. Compared to Asians, type 0 BAV was more frequently among Europeans, whereas the incidence of RN-BAV with a raphe was higher in Asian (Kong et al., 2018). Aortic stiffness was measured by pulse wave velocity (PWV) using velocity-encoded magnetic resonance imaging (VENC-MRI) and patients with R-NC fusion were manifested as greater PWV than patients with R-L fusion phenotype. This assessment might be a novel parameter to evaluate surgical risk (Boonyasirinant et al., 2018).

In order to show the relationship between BAV morphology type and valvulopathy or aortopathy, the dichotomous classification method was introduced in Figure 1B. The right and left coronary leaflet cusp fusion was defined as the coronary cusp fusion (CCF) and all other types were defined as the mixed cusp fusion (MCF). The MCF type of BAV was considered as one of risk factors for the occurrence of aortic stenosis and associated aortopathy, which resulted in significant hemodynamic changes. Transthoracic echocardiography (TTE) imaging that has characteristics of accuracy and feasibility makes this classification be a valuable approach in routine use (Jilaihawi et al., 2016; Sun et al., 2017).

Transthoracic echocardiography was the preferred method for the diagnosis of valvular status in BAV patients. The classical shape, "fish-mouth," was appeared in the views of short-axis when the valve was step into systole. And the view of long-axis might also provide some abnormal manifestations of bicuspid valve in systole (Lee et al., 2015). TTE alone, however, is hard to determine presence/absence of raphe or position of the orifice of the coronary artery. TTE could identify valvular phenotype in $47.4 \%$ patients and 2D TEE might achieved to $90.1 \%$. But, $2 \mathrm{D}$ TEE images was hard to provide the precise phenotype in $9.9 \%$ BAV patients, where 3D TEE was effective. In patients who had short raphe or disappearance of the raphe due to calcification in aortic leaflets, 3D TEE might excel in providing important features about valve structure in experienced hands (Yakar et al., 2017). And another imaging method, color doppler, is a useful tool to identify immobile trileaflet aortic valves or bicuspid valve by commissural fusion (Lee et al., 2015).

In order to preferable evaluate the aortic valve, the anatomy of aortic root especially the three-dimensional anatomy must be comprehended intensively. The aortic root is consisted of three distinct entities, including the sino-tubular junction (STJ), aortic sinus and the annulus. The aortic sinus contains the leaflets of aortic valve, the attachments of the leaflet, the sinuses of Valsalva and inter leaflet trigones. The annulus encompasses basal ring, the surgical annulus and the anatomical ventriculo-aortic junction (VAJ). The basal ring, an elliptical shape ring, is defined as a ring with three anchors at the bottom of each attachments of aortic cusps and calcification makes its shape non-homogenous. The surgical annulus, straddling the entire aortic root lengthwise from basal ring to STJ, is characterized as a complex threedimensional crown-shaped structure, which the lowest parts are nadirs of the sinuses of Valsalva, and the highest ones are the commissures (Komiya, 2015). The ventriculo-aortic junction (VAJ) is a circle which is positioned slightly above the basal ring between the aortic wall and left ventricular myocardium. Patients who received the aortic valve repair, the mean diameter of VAJ in tricuspid exceeding $26 \mathrm{~mm}$ and the mean diameter of VAJ in bicuspid valve exceeding $28 \mathrm{~mm}$ are defined as relative VAJ enlargement (de Kerchove et al., 2012).

The functional aortic annulus (FAA) which seems as elliptical was surrounded by VAJ and STJ at the aortic root. In order to interpretation the different dilatation in all FAA, El et al. (2005) recommended the classification of FAA which aimed to recognize different type of aortic regurgitation. In clinical, the most common phenotypes in BAV repair are El Khoury types Ib and II, which based on Sievers type 1 L-R BAV (Bavaria et al., 2013). Type-IB AR is caused by sinuses of Valsalva dilatation which is excised and replaced with the help of reimplantation or the remodeling technique. Type-II AR is secondary to excessive cusp or commissural disruption, which is corrected with interrupted sub-commissural annuloplasty plication sutures (El et al., 2005). It is suggested that three dimensions transesophageal echocardiography (3D TEE) and multidetector computed axial tomography (MDCT) were effective in evaluating FAA and most important of all, MDCT is recommend as a criterion imaging technique used to device sizing in the operation of TAVR (Jilaihawi et al., 2012). CT area possessed the highest correlation and the best agreement with intraoperative sizing, which leading 84.6 and $74.0 \%$ of BAVs to agree for theoretical surgical with TAVR prosthesis selection (Patel et al., 2015). Through 3DTEE could be used as an alternative for CT in BAVs patients who unsuitable for CT, it still need to be paid more attention especially in patients with aortic annulus calcification because inaccuracy could be caused by partial acoustic shadowing (Wang Y. et al., 2018).

In the era of TAVR, it is important to understand the aortic root anatomy precisely, which is the basis for device development, selection and implantation. In BAV patients, 
A
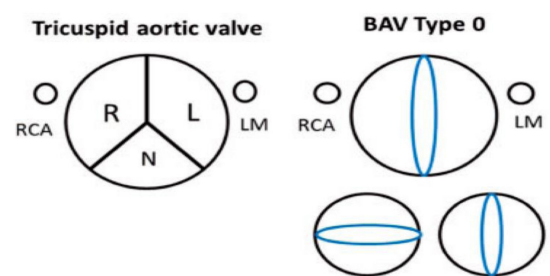

horizontal
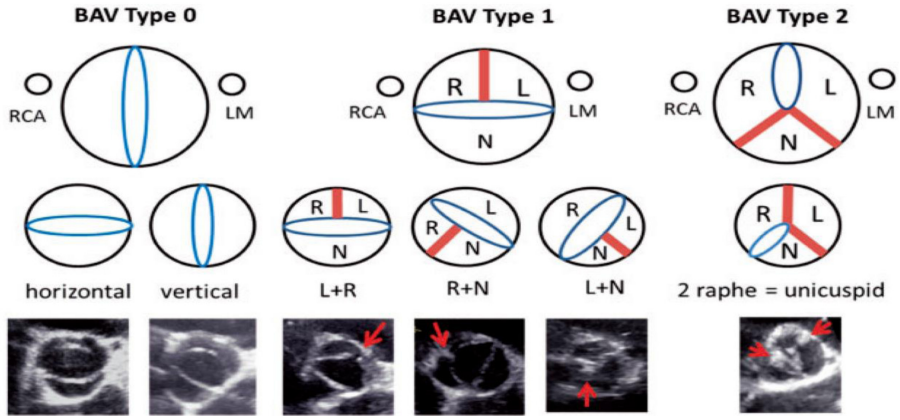

B

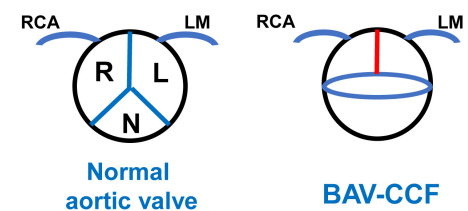

Dichotomous

aortic valve

BAV-CCF

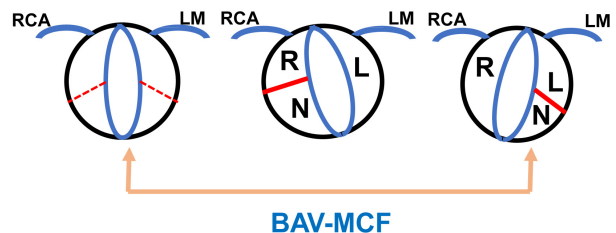

BAV-MCF

FIGURE 1 | Schematic diagram and images of different bicuspid aortic valve morphology. The Sievers classification and echocardiographic images are shown in (A). Dichotomous classification is shown in (B). Red bands and arrows represent the raphe or commissural fusion. Red dotted lines represent that patients with BAV has the fusion of the non-coronary cusp with the right coronary cusp or the left coronary cusp but it is hard to demonstrate raphe to adequately classify the subtype. The ostium of right coronary artery (RCA) is depicted on the left and the left main ( $L M)$ is on the right (A used with permission).

the sizes of annulus, sinus of Valsalva and ascending aorta have been enlarged. Traditionally, exclusion diagnosis is the standard diagnostic method for BAV because of asymmetric aortic annulus. This anatomical feature might cause leaflet malformation, even para-valvular leak due to asymmetric deformation and expansion of the rounded bioprosthesis (Zegdi et al., 2008). However, the larger annulus of BAV seems to be a circle and could be suitable for current commercial valved stents (Philip et al., 2015).

Sizing the aortic valve annulus that is representing the tightest section of aortic root based on the anatomy, which is suggested to be a valuable method in selecting the size of transcatheter heart valve (THV). The morphological characteristics of supra-annulus that is a scope locating from annulus to the STJ is becoming significantly complex when bicuspid AS combines with severe calcification in leaflets. Annulus measurements using CT might be inaccurate because the definition of the annulus plane derive from two hinge points of the leaflet. The supra-annular structure might have great effects on anchoring THV. Patients who have been diagnosed BAV manifest as morphological changes in valve including annular eccentricity, asymmetrical calcified leaflet, presenting different sizes of leaflets, and following by aortopathy, which increases the possibilities of deeper implantation, PVL, TAV-in-TAV, annulus rupture, aortic dissection (Zhao et al., 2015). Though CT have advantages in providing anatomic aortic root information, the mechanical characteristics of the annulus or supra-annular structure for THV anchoring could not be revealed completely. However, Balloon sizing, not descripted before, could provide the information about supra-annular mechanical characteristics through the sign of balloon waist combination with contrast aortogram and AR evaluation (Liu et al., 2018).
It is critical to select appropriate valve size after TAVI, which could promote rehabilitation. As a valid compensation for multimodality imaging, Balloon sizing has its own characteristics. Although there is smaller anticipated sizing ratio, the incidence of PAR after valve deployment and short-term follow-up does not increase after switching to smaller THV with balloon sizing. With the help of MSCT, patients with smaller valves possessed better stent frame expansion at inflow and a trend toward better frame geometry in terms of circularity than those who received valves of the same size or larger. Although MSCT has extraordinary effect in THV size selecting, balloon sizing could be used as a complementary tool as well as for BAV morphology assessment (Xu et al., 2018).

Early repair failure is associated with failure to address the functional aortic annulus in the process of BAV repairment. The deep anterior dissection technique not only avert the problem, but also acquires another goals including making the annuloplasty ring surrounded by the basal ring, permitting to symmetrical implantation, making the tissues of the root anteriorly become thin, causing less muscle bands and improving the accuracy of grafting sizing and matching and preventing recurrence of dilatation in the same area and prolapse of conjoined cusp by IVS (Nawaytou et al., 2018).

However, we speculated that aortic valve annulus eccentricity might be innate in infant and early child period. Children who manifest as severe or critical aortic stenosis usually are treated with aortic balloon valvuloplasty, rather than transcatheter AV replacements. $2 \mathrm{D}$ angiographic examination of parasternal long axis could assess the size of the aortic valve annulus in pediatric patients at present. The incidence of aortic insufficiency is increasing, as well as residual stenosis, when the size of eccentric annulus is inaccuracy. We suggest that aortic ballon valvuloplasty 
might help with therapeutic effects when taking the different annular size into account (Chamberland et al., 2015).

\section{GENETICS: POLYMORPHISM AND COMPLEXITY OF THE PATHOGENESIS}

It is well known that the genetic etiologies of BAV have the characteristic of diversity, which has the same characteristic with BAV phenotypes. BAV was an autosomal-dominant disease and had a highly heritable trait which was up to $89 \%$ (Freeze et al., 2016). Several investigators had shed light upon the mechanism induced by gene mutation in the development of BAV. NOTCH1 mutations were highly penetrant (75\%), most of which were BAV (Kerstjens-Frederikse et al., 2016). NOTCH1 combined with different ligands at different stages of morphogenetic processes to express variant regulatory effects. Delta-like 4 (Dll4), one of NOTCH ligand, was necessary for epithelial-to-mesenchyme transition formation, and endocardial Jag1-NOTCH1 signaling was essential for later morphogenesis and regulation of mesenchyme proliferation in post epithelial-tomesenchyme transition (MacGrogan et al., 2016). Additionally, NOTCH1 could affect calcium deposition through inhibition Runx2 activation. In the shear stress condition, NOTCH1 haploinsufficiency led to calcification of endocardial cells by dysregulating the downstream transcription of genes, inflammation, oxidative stress and aberrant upregulating procalcific nodes (Theodoris et al., 2015). It has been reported that endothelial progenitor cells (EPC) played a critical role in vascular repair processes during stress and development of aortic aneurysms. Compared with TAV patients, the expression level of Notch gene in tissue and circulation was significantly reduced in BAV patients, which directly reduced circulating EPC number, either in presence or absence of ascending aortic aneurysm (Balistreri et al., 2018).

The GATA family is a class of zinc finger proteins. The subgroup, GATA5, was a transcription factor, which was expressed in an overlapping together with GATA4 and GATA6 (Padang et al., 2012). The fusion of aortic valve in GATA5 deletion mice was presented in posterior intercalated cushion and septal ridge, resulting in RN BAV. Hence, the effect of GATA5 mutation might be more important in RN type BAV patients (Laforest et al., 2011). GATA4 was critical for heart differentiation. Two genetic variants have been identified that approached even achieved to genomewide levels. The rs6601627, representing a low-frequency intergenic variant, has a higher incidence rate in BAV patients. The rs3729856 variant was associated with protein expression, which involved in specific gene transcription in cardiac (Yang et al., 2017). GATA6, another GATA family member, might be a novel BAV causing gene. GATA6 heterozygous mice had highly penetrant RL type BAV, the most common type in human. GATA6 haploinsufficiency undermined valve remodeling and extracellular matrix composition through dysregulation of important signaling molecules including matrix metalloproteinase 9. Defective valve remodeling due to dysregulated extracellular matrix degradation has been suggested to be potential mechanism in BAV formation (Michelena et al.,
TABLE 1 | Main genetic mutations determining bicuspid aortic valve.

\begin{tabular}{|c|c|c|}
\hline Gene & Mechanism & Reference \\
\hline $\mathrm{NOTCH} 1$ & $\begin{array}{l}\text { Affect epithelial-to-mesenchyme } \\
\text { transition formation and calcium } \\
\text { deposition and reduce circulating } \\
\text { EPC number }\end{array}$ & $\begin{array}{l}\text { Theodoris et al., 2015; } \\
\text { Kerstjens-Frederikse } \\
\text { et al., 2016; } \\
\text { MacGrogan et al., } \\
\text { 2016; } \\
\text { Balistreri et al., } 2018\end{array}$ \\
\hline GATA 5 & Associated with RN BAV formation & Laforest et al., 2011 \\
\hline GATA 4 & $\begin{array}{l}\text { Impair endothelial-to-mesenchymal } \\
\text { transition }\end{array}$ & Yang et al., 2017 \\
\hline GATA 6 & $\begin{array}{l}\text { Undermine valve remodeling and } \\
\text { EMC by dysregulation of MMP9 }\end{array}$ & Michelena et al., 2014 \\
\hline $\begin{array}{l}\text { ACTA2, FBN1, } \\
\text { TGFBR2 }\end{array}$ & $\begin{array}{l}\text { Involved in thoracic aortic aneurysm } \\
\text { caused by BAV, Marfan syndrome, } \\
\text { Loeys-Dietz syndrome }\end{array}$ & Giusti et al., 2017 \\
\hline $\begin{array}{l}\text { WNT/ } \beta \text {-catenin } \\
\text { or RTK/p-AKT }\end{array}$ & $\begin{array}{l}\text { Aberrant signaling pathway } \\
\text { involved in BAV ascending aortic } \\
\text { and aneurysm }\end{array}$ & $\begin{array}{l}\text { Hirata et al., 2018; } \\
\text { Yamashita et al., } 2018\end{array}$ \\
\hline \multicolumn{3}{|l|}{$\begin{array}{l}\text { New loci on } \\
\text { chromosome }\end{array}$} \\
\hline $\begin{array}{l}\text { 1p21 near } \\
\text { rs7543130 }\end{array}$ & $\begin{array}{l}\text { Associated with increased aortic } \\
\text { root size in BAV }\end{array}$ & Helgadottir et al., 2018 \\
\hline $\begin{array}{l}2 q 22 \text { in } \\
\text { rs1830321 }\end{array}$ & $\begin{array}{l}\text { Associated with BAV and coronary } \\
\text { artery disease }\end{array}$ & \\
\hline
\end{tabular}

2014). But common variants at the GATA6 locus associated with BAV were unclear. Of note, although the relation between GATA6 and BAV in human has not been illuminated, the prevalence of BAV is greater in male GATA6+/- mice than female (Gharibeh et al., 2018).

Other mutated gene often correlated with specific features and prognosis. Due to abnormal flow in BAV aneurysm, the aberrant methylation of epithelial-mesenchymal-transition and increased expression of WNT/ $\beta$-catenin genes like MYLK, ZEB1 were involved (Bjorck et al., 2018). Besides, transcriptome analyses and immunohistochemical study of ascending aortic specimens from BAV patients showed that receptor tyrosine kinase $(\mathrm{RTK}) / \mathrm{p}$ AKT pathway in the middle part of ascending aortic wall was activated, in spite of the constant expression level of total AKT (Hirata et al., 2018; Yamashita et al., 2018). Mutations in ACTA2, FBN1, and TGFBR2 genes might be the reason of BAVs with thoracic aortic aneurysm (Giusti et al., 2017). Two new aortic valve stenosis loci, named rs7543130 on chromosome 1p21 near PALMD or rs1830321 on chromosome 2q22 in TEX41, might be involved in the development of BAV. Rs7543130 associated with BAV and aortic root diameter, and rs1830321 associated with BAV and coronary artery disease (Helgadottir et al., 2018). Genetic mutations above determining bicuspid aortic valve are summarized in Table $\mathbf{1}$.

\section{BIOMARKERS OF BAV: PROSPECTIVE IN DIAGNOSIS AND TREATMENT}

Although BAV is a hereditary disease and most BAV patients are asymptomatic at onset, we still hope to explore some molecular biological markers to speculate the progression of 
BAV. Matrix metalloproteinase (MMP) would affect degradation of extracellular matrix proteins such as elastin and collagen in the aortic wall (Phillippi et al., 2009). The increased MMP-2 level in circulation could predict the ascending aortic dilation in BAV patients independently without significant valvular dysfunction (Wang et al., 2016; Wang Y.B. et al., 2018). TGF- $\beta$ and its receptor ENG correlated with the severity of the development of aortic dilation in bicuspid aortic stenosis patients. The signaling pathway played a vital role in fibrosis, inflammation and extracellular matrix of cardiovascular system. There might be a relationship between TGF- $\beta 1 /$ ENG ratio and aortic diameter. When aortic diameter $<45 \mathrm{~mm}$, the ratio becomes higher and abnormal aortic wall remodeling comes even more severer with increasing expression of MMP-2 and TGF- $\beta$ as well as decreasing expression of superoxide dismutase 3. And, the ratio has positive correlation with the rate of ascending aortic growth in AVR postoperative period of bicuspid aortic stenosis patients. Therefore, the ratio of TGF- $\beta 1 / \mathrm{ENG}$ might be a novel predictor for the risk and severity of BAV aortopathy (Forte et al., 2017). However, the development of aneurysms in patients with BAV was not associated with an increased TGF $\beta$ activity (Paloschi et al., 2015). In stenotic aortic leaflets from BAV patients compared with TAVs, the downregulation of miR-195 was associated with accelerated valvular calcification via targeting SMAD7, which involved the progress of fibrosis and remodeling of the extracellular matrix (Du et al., 2017). In addition, miR-17 could indicate different part of aorta dilation by regulating expression of TIMP1/2 and MMP2. In normal aorta, the expression of miR17 and related miRNAs was low. And the level of TIMP1/2 was normal, inhibiting MMP2 activity. During the early phase of BAV-associated dilation, miR-17 was upregulated, inhibiting TIMP1/2, which subsequently increased MMP-2 activity, leading to progressive extracellular matrix breakdown, aortic dilation and aneurysm formation. Once severe tissue dilation had occurred, miR-17 expression was reduced, TIMP1/2 expression increased, and MMP-2 activity decreased toward baseline levels (Wu et al., 2016). The expression of proteins and miRNAs might be a potential prognostic biomarker for predicting pathological aorta in BAV patients. Optimal therapies targeted at different proteins and miRNAs were not only novel treatments of aortic complications in BAV patients, but also preventing early stages of disease development before irreversible valve calcification, aorta became dilated severely and aortic aneurysm was formed aggressively. To date, the research about biomarkers that was used to early diagnose BAV clinically is still at its infancy. However, the truth on those markers has not been uncovered. And further investigations in large patient cohorts are needed to provide strong data.

\section{BAV ASSOCIATED COMPLICATIONS: THE SUPPLEMENT FOR GUIDELINE DIAGNOSIS AND TREATMENT}

The BAV was not only just a valve disease, but also it was related to secondary aortic stenosis, aortic insufficiency, infective endocarditis and cardiac dysfunction. Due to the influence in gene and abnormal aortic blood flow, BAV patients would suffer from ascending aortic dilated and aneurysm. So far, the most strategic therapy is operation at appropriate time and prevent complications. In this part, we provide a brief introduction and supplement of diagnose and treatment for BAV.

\section{BICUSPID VALVULOPATHY: A COMPLICATION WITH HIGH INCIDENCE AND INDUCED LEFT VENTRICLE DYSFUNCTION NEED TO PAY MORE ATTENTION}

A recent report about prevalence and complications of BAV in Chinese, suggested that almost half of the patients who were diagnosed BAV had different degrees of aortic valve disease with similar results in western report (Li et al., 2017; Masri et al., 2017b). In the large international registry of 2118 patients with $\mathrm{BAV}$, compared with patients with raphe, the prevalence of aortic stenosis and aortic regurgitation was lower in patients who have no raphe. The 2 raphes was associated with higher prevalence of significant aortic stenosis and regurgitation compared with the 1 raphe. Among patients with 1 raphe, RN-BAVs had more aortic stenosis. Due to valvular dysfunction at a younger age, BAV patients with raphe prefer to perform AVR, but not related with an increased risk for all-cause mortality (Kong et al., 2017).

\section{AORTIC STENOSIS: MULTIPLE IMAGING TECHNOLOGY EVALUATION}

As one of major risk factors, BAV was involved in mild to severe AS. TTE has been recommended in bicuspid aortic valve patients with symptoms. It could provide precise diagnosis of abnormal hemodynamic and left ventricle function. And, TTE might be used to decide the surgical intervention time and speculate prognosis (Nishimura et al., 2014). TTE derived left ventricular outflow tract (LVOT) area might be inaccurate because of single diameter of elliptical aortic root. Compared with the aortic valve area-ECHO (AVA ECHO), the AVA CT (aortic valve area was calculated by MDCT) was larger overall in BAVs, but could not show the relation to transvalvular gradient, the concordance gradient-AVA, or speculated mortality. When AVA was evaluated with CT $(<1.2 \mathrm{~cm})$ and Echo $(<1.0 \mathrm{~cm})$, larger cut-point values might be a valuable parameter in severe AS diagnosis (Clavel et al., 2015). Fusion imaging might provide a more accurate assessment of the "true" AVA by decreasing the rate of discordant AS with low gradient but increasing the rate of discordant AS with high gradient (Arangalage et al., 2018). In clinical, it is crucial to accurately diagnose the severity of AS with the help of routine doppler because of characteristics of multiple imaging windows (Thaden et al., 2015). Ejection dynamics, particularly acceleration time (AT) and the ratio of AT to ejection time (ET), could be applied to evaluate AS severity (Gamaza-Chulian et al., 2017). In addition, doppler 
ultrasonography was used to evaluate transvalvular pressure drop using the simplified Bernoulli formulation to measure the severity of AS. Recently, a formulation that is corrected to calculate the cross-sectional profile of blood flow was used to estimate peak pressure drops accurately (Donati et al., 2017). Cardiac computed tomography could be recommended in younger BAV patients could with higher sensitivity and specificity. Although valvular calcification of the BAV had a faster progress in younger patients, there might be a hemodynamically significant stenosis without aortic valve calcification (Shen et al., 2017). As WSS is important in evaluating viscous shear forces on vessel wall due to abnormal flowing blood. 4-dimensional (4D) flow MRI measured volumetric velocity vector fields which could represent the increased regional WSS (Dyverfeldt et al., 2015). Increased WSS in bicuspid AS patients distributed mainly along the ascending aorta, especially at the outer curvature. This was consistent with the fact that aortic dilatation in BAV patients was asymmetrically. The degree of elevated WSS was negatively related to aortic diameters. Therefore, in BAV patients, the elevated WSS of the ascending aorta was related to aortic valve stenosis and aortic dilatation, which was more obviously when patients manifested as AS and nondilated ascending aorta (Farag et al., 2018). If decomposed the WSS vector field into its axial and circumferential components (WSSA and WSSC) from 4D flow MRI data using a Laplacian approach, the average WSSC in the ascending aorta was statistically significant difference as a parameter for evaluating multidirectional flow in complex geometries (Sotelo et al., 2018).

In recent years, the proportion of bicuspid aortic stenosis patients who has been carried out TAVR is increasing with a tendency to younger patients. However, TAVR might meet different procedural changes. For Sievers type 0 patients with no raphe, the challenge might be an ellipse aortic annulus than a circle and the risk for paravalvular leakage. LR BAV patients might confront with the risk of imprecise allocation, due to the calcified raphe which placed unequal stress on the dilatation of a TAVR (Ben-Dor and Stewart, 2017). In respect of procedural threat of TAVR, the new generation devices including ballon-expandable Sapien 3 and Lotus valve could overcome the crucial limitation of previous devices such as obvious perivalvular leak, failure to get optimal positioning and associated vascular complications (Mylotte et al., 2014; Yang et al., 2015; Perlman et al., 2016; Yoon et al., 2016, 2017; Sannino et al., 2017). Transcatheter balloon aortic valvuloplasty was considered palliative therapy for BAV as well as a useful tool in sizing ascending aorta. Currently operators used a median effective final balloon to aortic valve annulus ratio of 0.94 as criterion (Boe et al., 2017). However, the optimal approach for sizing in bicuspid aortic stenosis was controversial. Some recommended perimeter/area at the annulus level as criterion, and the others suggested to use the commissural level above the annulus about $4-8 \mathrm{~mm}$ as the sizing selection (Ben-Dor and Stewart, 2017). To date, TAVR with the help of the newgeneration device is a reasonable treatment option with the good outcome and low complication rate for bicuspid AS patients.

\section{AORTIC REGURGITATION: DIFFERENT SURGICAL INTERVENTIONS}

Aortic regurgitation is more frequent in the earlier period of patient's life than stenosis (Okita, 2015). Once aortic regurgitation is formed, the major factor affecting the development is left ventricular pathological change due to chronic volume overload. As a result, surgical intervention will be the final decision for most bicuspid AR patients (Braverman et al., 2005). We have a brief introduction including an assessment of degree of bicuspid AR and left ventricular function and different surgical interventions.

Transthoracic echocardiography is a preferred imaging test for evaluating bicuspid AR patients and guiding appropriate management decisions. Cardiac catheterization might be a valuable method to evaluate abnormal hemodynamics, anatomical structure of coronary artery and development of aortic regurgitation (Nishimura et al., 2014). Eccentric jet was common in BAV valve malformation, and it was difficult to accurately assess bicuspid AR with ultrasound. When eccentric jet was hard to be quantified and LV dilation was disproportionate to the degree of $\mathrm{AR}$, cardiac MR might give a better way to quantity AR and LV volumes (Mojazi-Amiri and Pai, 2013). In a study on the character of speckle-tracking echocardiography in terms of judgment cardiac function, assessment of circumferential as well as longitudinal strains was important. For asymptomatic patients with hemodynamically significant bicuspid AR, global circumferential strain (GCS) and global longitudinal strain (GLS) were lower compared with healthy. GCS compensated for the reduced GLS to ensure that global function and left ventricular ejection fraction (LVEF) remained in the normal range. However, the study showed no association between LVEF and GLS, whereas GCS was correlated with LVEF (Broch et al., 2017).

The majority of patients would require AVR, exception of severe AR with $\mathrm{LVEF} \geq 50 \%$, LVESD $\leq 50 \mathrm{~mm}$, LVEDD $\leq 65 \mathrm{~mm}$ or progressive AR without other cardiac surgery. The most frequent valve-related complication leading to re-operation had been recurrence of $\mathrm{AR}$ induced by dilatation of the aortic root. For mild bicuspid BAV patients with aortic root dilation ( $>40 \mathrm{~mm}$ ) during their initial AVR procedure, the surgical intervention could be considered to decrease the incidence of recurrent AR (Girdauskas et al., 2017). If the regurgitation BAV patient combines with annular dilatation, the repair treatment might not be successful. Sub-commissural annuloplasty resulted in earlier repair failures compared with complete circumferential annuloplasty (Navarra et al., 2013; Nawaytou et al., 2018). Suture annuloplasty with polytetrafluorethylene as material could eliminated annular dilatation and reduce local complications and tissue trauma. Suture annuloplasty should be considered whenever basal diameter exceeds $26-27 \mathrm{~mm}$. The stability could be comparable to valve preserving aortic root replacement without the associated complexity of the procedure. After aortic valve repair, the height of coaptation was considered acceptable if vena contracta was $\geq 4 \mathrm{~mm}$ on TEE (Schneider et al., 2017). Valve-sparing aortic root replacement (VSSR) could be a promising option for aortic regurgitation patients, which might 
improve repair durability, especially annulus stabilization, and should be recommended in young patients (Komiya, 2015).

\section{INFECTIVE ENDOCARDITIS: ANTIBIOTIC PROPHYLAXIS COMES FIRST}

BAV patients were more likely to have infective endocarditis (IE) than the others (Siu and Silversides, 2010). The majority of BAV with IE were men. Adverse events of IE included heart failure, peripheral embolism, embolic stroke, persistent bacteremia, and intracardiac complications (Chambers, 2018; Zegri-Reiriz et al., 2018).

The most common organisms causing IE were microorganisms presented in the oral cavity, mainly viridians group streptococci. BAV should be considered as high-risk cardiac conditions with unrestricted IE antibiotic prophylaxis (Chambers, 2018). The signs of IE in TTE performance included vegetation, valvular perforation, and perivalvular abscess. There were no significant differences among left atrial diameter (LAD), left ventricular end-diastolic diameter (LVEDD), and left ventricular end-systolic diameter (LVESD) values like the incidences of serious AR or AS. Given the high frequency of perivalvular abscesses in BAV IE patients, systematic use of TTE or TEE in all BAV IE patients and prompt diagnosis of perivalvular abscesses are necessary and advantageous for the prognosis (Chen et al., 2017). In order to treat infection and avoid the sequelae resulting from tissue destruction of valve and paravalvular, surgical intervention was recommended, especially at early stage. To date, there was few long-term in multicentric follow-up study for BAV patients with infective endocarditis to verify the rationality of the current guidelines. For patients with BAV, cardiac echocardiography should be taken regularly to prevent the disease before getting worse.

\section{LEFT VENTRICLE DYSFUNCTION: IMPORTANT BUT UNCLEAR RELATIONSHIP WITH BAV}

Under the presence of abnormal hemodynamics and aberrant gene expressions like TGF- $\beta$, NOTCH and MMPs, it might affect left ventricular function and lead to LV remodeling including myocardial hypertrophy and fibrosis. Although we did not have clear understanding about the relationship between BAV and myocardial hypertrophy, the data has showed that $0.9 \%$ of the HCM patients suffered from BAV and $0.4 \%$ of BAV patients were coexistent with HCM. 11 patients developed into dynamic obstruction, which always affect the LVOT. Resting obstruction was presented in five patients, which presented the gradient $\pm 30 \mathrm{mmHg}$ (Padang et al., 2018). Collagen volume fraction (CVF) was reduced in sub endocardium and increased in endocardium. This might imply endocardial fibrosis in severe AS and AS was one of major complications of BAV as mentioned before. We speculate that endocardial fibrosis might exist in part of BAV patients (Treibel et al., 2018). Late gadolinium enhancement (LGE) on MRI imaging has been used to identify the presence, pattern, and size of fibrosis as well as myocardial and cardiomyopathy (Ambale-Venkatesh and Lima, 2015; Gaztanaga et al., 2016). In a retrospective study with 29 BAV patients, CMR and TTE images were reviewed. Patients with LGE had significantly higher aortic valve mean gradients by TTE and were more likely to have LV hypertrophy. They were more likely to need aortic valve replacement within 1 year. Evaluation of LGE by CMR as a marker of LV myocardial fibrosis could have additional prognostic value (Lluri et al., 2017). CMR is a non-invasive approach used to measure LV mass and volume and a valuable tool used to describe the LV remodeling in response to AS, which is regarded as a gold standard. BAV patients were demonstrated to have significantly larger left ventricular outflow tract dimensions (LVOTd), systolic LV area, LV end-diastolic volume (LVEDV), LV end-systolic volume (LVESV). The LVOTd is significant related with maximal aortic root diameters at all levels in BAV patients, especially with the aortic annulus diameter. But the correlation between LVOTd and mid-ascending aortic diameter was weak (Disha et al., 2017). The blood flow is strong eccentricity, which is presented in all degrees of AS. Alteration in poststenotic blood flow when AS is presented is the reason for elevating $\mathrm{LV}$ after load. The relationship between LV remodeling and aortic orifice area ( $\mathrm{AOA}$ ) emphasizes the notion that remodeling is a characteristic of all degrees of AS. The intensity of abnormal blood flow increases with the decreasing of AOA, and increases further with the presence of BAV. In addition to AOA, it is suggested that the flow parameter normalized flow displacement is an alternative sign for defective blood transporting and eccentric myocardial stress because it is in connection with LV remodeling. Different grades of AS were involved in elevated and asymmetrical WSS distribution. However, there is no correlation between it and LV remodeling. And the mechanotransduction risks of poststenotic dilatation should be paid more attention as it might happen in early period of AS (von Knobelsdorff-Brenkenhoff et al., 2016). The mass index and indexed volumes of LV or the ratio of LV mass/volume are always measured to explore the extent and patterns of hypertrophy. A specific wall thickening of the myocardial, no less than $13 \mathrm{~mm}$ or 1.5 times larger than the opposing one, is regarded as asymmetric remodeling and hypertrophy. There are as many as six patterns of LV adaption including normal ventricular, concentric remodeling, asymmetric remodeling, concentric hypertrophy, asymmetric hypertrophy and LV decompensation. Despite unstable, the increased stress of LV still could cause extensive LV impairment (Dweck et al., 2012). TTE is used to assess the systolic longitudinal strain which is a valuable indication to early LV disorder of AS. Decreasing in LV ejection fraction indicates that the LV dysfunction is stepping into the late stage ( $\mathrm{Ng}$ et al., 2011; Pibarot and Dumesnil, 2012). However, there seems to be no significant correlation between pattern of LV adaption or degree of hypertrophy and BAV classification. Although the women BAV patients were more likely to have aortic stenosis, there was no significant differences in sex regarding left ventricular function assessed by cardiac MRI (Dweck et al., 2012). 
In some BAV patients without aortic valve dysfunction and ascending aortic dilatation, cardiovascular MR tissue tracking imaging has demonstrated that ascending aortic and LV systolic and diastolic myocardial mechanics in all the three vectors (longitudinal, circumferential, and radial) are significantly impaired. The aortic valve congenital abnormality seems to be the only reason to cause LV impairment. That is to say, BAV may be not only a disease of aortic valve and aortic wall but also an inherent disease of the LV myocardium. This is a compelling evidence that the remodeling process of $\mathrm{LV}$ is associated with BAV, which has been debated for long (Nucifora et al., 2018). For asymptomatic BAV patients with preserved EF, feature-tracking CMR (CMR-FT) may be a useful and practical tool for assessing LV function. The impaired diastolic function caused by myocardial hypertrophy and fibrosis precedes systolic abnormalities and could predict the outcomes of surgical in patients with aortic stenosis. In asymptomatic BAV patients who have no signs of ventricular dysfunction by routine cardiac MRI, CMR-FT strain analysis can detect myocardial dysfunction especially when the diastolic strain rate decreased. With the improvement of surgery and diagnosis which could identify patients at younger age, the survival time of postsurgery patients has been extended. But continues monitoring LV function is still necessary. More attention should be paid to changes about cardiac structure and function to prevent LV dysfunction.

\section{BAV-ASSOCIATED AORTOPATHY: MORE CRITERION ABOUT ASSESSMENT AND TREATMENT SHOULD BE INCLUDED EXPECT FOR AORTIC DIAMETER}

The BAV-associated aortopathy has a prevalence of $40 \%$ in patients of multiple clinical centers. In contrast to general population, BAV patients were 86 times to develop proximal aortic aneurysms and 8 times to have aortic dissection. The morbidity of aortic dissection and rupture were about $0.4 \%$ during 2-16 years. The proportion of aortic rupture was very low, which there is only one rupture in all 14 cases in a 32 months follow-up (Michelena et al., 2011; Kim et al., 2016; Masri et al., 2016). Cardiac cyst originated from bicuspid aortic valve was an extremely rare type of cardiac mass ( $\mathrm{Gu}$ et al., 2014).

\section{AORTIC DILATATION: THE ONSET OF BAV-ASSOCIATED AORTOPATHY}

Currently, there are two main theories on the relation between $\mathrm{BAV}$ and aortic dilatation: an underlying genetic substrate and hemodynamics theory. Gene mutations as mentioned above could not only causing the development of BAV but also exacerbating calcium deposition on the valve. The activity of MMPs is increased and fibrillin-1 expression is decreased in the wall of ascending aorta (Nataatmadja et al., 2003). Gradually, decreased collagen, increased elastic fragmentation, and reduced VSMCs in aortic middle layer degeneration lead to aortic convex surface before ascending aortic dilatation. And abnormal hemodynamics inside the ascending aortic will also cause uneven shear stress on the same area (Cotrufo et al., 2005). This has a promotional effect in increasing expression of MMPs and VSMC apoptosis (Lehoux and Tedgui, 2003). And a stronger hemodynamic influence might play an important role in BAV patients who have tubular and stiff ascending aortic dilation (Yassine et al., 2017). Not the stiffness index of all the aortic segments was higher than healthy. After adjusting the age and the aortic diameter, the sinus of Valsalva appeared to be the only segment significantly stiffer, which might suggest a local remodeling process in BAV patients (Goudot et al., 2018).

Aortic dilatation with BAV was classified as three types: type 1 was dilatation of root, ascending and proximal arch aorta dilation along convexity of aorta. Type 2 was relative normal root with tubular ascending aorta dilation. Type 3 was isolated dilatation of aortic root alone (Verma and Siu, 2014). The location of aorta dilation was related to valve morphology, sex and bicuspid valvulopathy. RN-BAVs and RL-BAVs would induce dilation of different aortic part, which the dilation induced by RN-BAVs was located in ascending aorta, whereas the one induced by RL-BAVs was aortic root (Ruzmetov et al., 2015; Krieger and Hung, 2018). AR could result in diffuse enlargement including annular, sinus of Valsalva, and ascending aortic, whereas AS of moderate to severe grade only led to ascending aortic enlargement. The diameter of sinus of Valsalva was larger in men when compared with women, whereas ascending aortic diameters were comparable (Roman et al., 2017). In addition, abnormal ratio of ascending aortic area/height, as well as sinus of Valsalva and ascending aortic dilatation rate might be regarded as predictors of cardiovascular death (Detaint et al., 2014; Masri et al., 2017a).

2D TTE is a feasible, accurate, and reproducible method for the non-invasive assessment of thoracic aortic diameters. It has been reported that unbiased agreement could be obtained between the CTA inner edge-to-inner edge method and TTE leading edge-to-leading edge method for the sinuses and ascending aortic (Park et al., 2017). Aortic WSS correlated with regional elastic fiber thinning was heterogeneous within the aorta of an individual patient with BAV. The association between WSS and regional histopathology was the most closely, which predominant manifested as AS and mildly aortic dilation $(<4.5 \mathrm{~cm})$ (Barker et al., 2018; Bollache et al., 2018).

After repeated modifications in different international guidelines on BAV aortopathy, AAR (ascending aorta replacement) might be a suitable option for patients with severe AS or AR who have suffered AVR, when diameter of aorta was $>4.5 \mathrm{~cm}$ (Hiratzka et al., 2016; Nishimura et al., 2017). When the situation that the dilation of aortas reaches $5.1-5.5 \mathrm{~cm}$ and aortic dissection or aortic growth rate $\geq 0.5 \mathrm{~cm}$ per year is presented in family history, aortic repair operation could be recommended (Hiratzka et al., 2016). Mid-term imaging after AVR and AAR indicated that prophylactic root replacement will be unnecessary in case that aortic root is not dilated in surgery, because of unlikely aortic root enlargement later in patients (Hui et al., 2018). 


\section{AORTIC ANEURYSM AND DISSECTION: NEED MORE PREDICTORS AND TIMELY RECOGNITION}

Once aortic dilation was suspected, the entire aorta and affected parts which should be considered to be at risk for aortic aneurysm or dissection. Although aorta diameter $\geq 40 \mathrm{~mm}$ was considered to be aortic dilation in the 2014 AHA guideline, risk of aortic dissection was significantly correlated with the aortic diameter. The estimated risk of aortic dissection gradually increases when diameter of the aorta becomes larger (Kim et al., 2016).

Due to aorta dynamic change with the heart contraction and diastole, aortic size alone was not enough to distinguish different pathological processes under the risk of acute complications. Other predictors about aortic wall and blood flow changes could be developed to assess the timing of surgical intervention (Bhave and Eagle, 2018). Wall shear stress, flow displacement and helicity were elevated in patients with BAV, particularly at locations of aneurysm formation (Bissell et al., 2013; Youssefi et al., 2017). The anterior region of ascending aortic aneurysm sample (the zone with lower curvature) was the most weakness and less stiff, resulting in the ascending aortic aneurysm expansion in such a region (Ferrara et al., 2018). This might provide the possible reason that patients with aortic diameter whose size do not meet surgical criteria are prone to acute aortic rupture or dissection. 4D flow MRI seemed to be a useful tool showing biphasic trend followed by dilated diameter of aneurysm. With the diameter of ascending aortic enlarged, it decreased firstly and increased. This curve has an obvious turning point as the diameter of ascending aortic was $50 \mathrm{~mm}$ (Guala et al., 2018). The single diameter of aortic root or ascending aortic should not be used as a basis for the possible formation of aortic dissection. The cross-sectional area to height ratio and patient specific aneurysm wall stress analysis were recommended to predict aortic dissection (Wojnarski et al., 2015; Hiratzka et al., 2016; Xuan et al., 2018). European and American guidelines for intervention for BAV aortic aneurysms are not consistent. In ESC guideline, interventions should be recommended for patients with ascending aortic diameter $\geq 50 \mathrm{~mm}$ and risk factors (Erbel et al., 2014b; Iung, 2015). In American guidelines, for patients of BAV, the diameter of ascending aortic or sinus is larger than $5.5 \mathrm{~cm}$, surgical repair should be assessed and recommended (Hiratzka et al., 2010).

As BAV with aortic aneurysm could progress to aortic dissections, timely recognition of aneurysm can be lifesaving due to the high mortality rate (Evangelista, 2016). Young adults were better treated with reimplantation of the aortic valve, as correction of annular dilation was important. The closer 2 main commissures are to $180^{\circ}$, the better the long-term results will be (David, 2016). For some young patients, the aortic cusps are nearly normal anatomically and morphologically, aortic valve-sparing root replacement was also an effective alternative (Ouzounian et al., 2016). In contrast, recent study provided that valve-sparing root replacement and bio-composite valve led to equivalent operative mortality and morbidity with similar midterm survival and valve durability (Esaki et al., 2017).
In emergency situation, aortic valve replacement could be performed to AD patients (Erbel et al., 2014a,b). Aortic valve resuspension with supra-coronary aortic replacement could be recommended to restore aortic valve competency in most $\mathrm{AD}$ patients with acceptable mid-term survival (Tang et al., 2017).

\section{PEDIATRIC BAV: CANNOT APPLY ADULT KNOWLEDGE}

Pediatric BAV, although similar to adult BAV, has different characteristics in disease development and treatment. According to Sievers classification, BAV morphology including type 0 (55\%), type $1(41 \%)$, and type 2 (4\%) in children (Merkx et al., 2017). At an early stage, some children with well-functioning BAV have abnormalities in some parameters of diastolic function of LV and even all parameters of proximal and distal ascending aortic elasticity. However, there is no relationship between the aortic stiffness and LV diastolic impairment (Weismann et al., 2016). $Z$-scores of children seem higher at the site of annulus, sinus valsalva, sinutubular junction, and ascending aorta. Moreover, the aortas start to enlarge in BAV patients from childhood and progress as time goes on, 0.06 (Gautier) and 0.09 (Campens) units per year at the age of 5-15 years, which delivers us a signal that generalized aortopathy has come around. The elasticity of aortas increases at young age and begins to decrease with age (Verma and Siu, 2014). In some pediatric patients with BAV, aortic growth is not proportional to body growth. The sizes of sinuses of Valsalva or ascending aorta seems to be larger, which might be associated with AR or AS. BAV morphology is a important factor that could directly affect the dilation of aortic sinus. Although the dilation of aortic sinus is not existing patients who manifests as $\mathrm{RN}$ fusion morphology, the median $Z$ score of aortic sinus is significantly higher in these who have RL fusion morphology, which is keeping in accordance with some conclusions obtained from adults (Jassal et al., 2010; Khoo et al., 2013). And the $\mathrm{RN}$ fusion morphology is associated with significantly greater incidence and undesirable prognosis of aortic valve stenosis and aortic insufficiency in contrast to ascending aorta (Ward et al., 2018).

For the patient with isolated, normal functioning BAV, echocardiography could be used to monitor development of BAV associated complications (Merkx et al., 2017). Due to the inaccuracy in measurement of aortic valve annular eccentricity through 2D echocardiography, therefore, 3D echocardiography could be a better choice to evaluate the AV annulus which has the shape of ellipse and keeps the same in all patients (Chamberland et al., 2015). On the contrary to adult patients, WSS seems to be not related to ascending aortic dilation in pediatric BAV patients after the valvular disease being controlled. The enlarging of aorta diameters causing the reduction of WSS, which takes place in adult BAV, will keep a long time and seems to be scarcely in pediatric BAV patients (Allen et al., 2015). Echocardiographic endpoints are measured as $z$-score, which manifests as progressive AS or AR and aortic enlargement at different levels of the aortic root. It is benign in the period of medium-term follow-up. It is suggested that the degree of AS 
was constant in $95 \%$ of patients and about $85 \%$ of the patients showed no increase in the degree of AR. Although the ascending aorta dilation was observed $(z$-score $>2)$ and the incidence was less than one-fifth of the patients, the progressive dilation was not existed in annulus, Valsalva sinuses, or sinotubular junction (Spaziani et al., 2014).

Stenosis is the dominating clinical feature in younger patients and regurgitant becomes predominant when patients are stepping into adulthood. It has been suggested that regurgitant valves are always accompany with stenotic parts that is the result of commissural fusion, which restricts the motion of the leaflet in pediatric patients (Siddiqui et al., 2013). There are six types of the dilated aorta in children with BAV including the normal shape (S1), the enlarged ascending aorta (S2), the effacement of the sinotubular ridge (S3), the Marfan-like (S4), the enlarged sinus of Valsalva and ascending aorta (S5), the normal annulus, and proximal sinus of Valsalva, enlarged distal sinus of Valsalva, sinotubular ridge, and ascending aorta (S6). S2 and S3 are more presented than other types. S3 becomes the dominating type with aortic dilation becoming more significant. Although some patients with S2 or S3 BAV shape have no aortic dilation, the ascending aorta was larger compared with normal aorta, which also suggested that the process of abnormal dilation might have already begun (Mart and McNerny, 2013).

The effect of surgical repair in pediatric BAV patients is excellent, especially no patches are attached. The primary repair is recommended because enduring results can be obtained with simple procedures. It is suggested that some patients underwent the surgery of bicuspid valve repairment without addition any patch material and there is no adverse events for up to 10 years because the valves used in the surgery is similar to the native valves. Up to now, compared with an extensive debridement of the valve, it is hard to identify the patients who will have a better prognosis. The ross procedure is recommended to carry out in adult age because a quarter of the patients need to replace their autografts within 2 decades, which we hope to create a situation that the root of autograft is reinforced more easily (Siddiqui et al., 2013). Aortic incompetence (AI) is the main reason for aortic valve balloon valvuloplasty surgery after BAV (Balmer et al., 2004). The degree of AI is closely related to the ratio of balloon/annulus, but not related to the valve morphology. Balloon valvuloplasty is associated with the decreasing mortality and could reduce acute postoperative complications, which root in the decreasing ratio of balloon/annulus that is a well-known risk factor to increase the acute complications (Knirsch et al., 2008).

\section{MARFAN AND LOEYS-DIETZ SYNDROME: SIMILAR WITH THE ASCENDING AORTIC DILATATION IN BAV}

Bicuspid aortic valve with aortic dilation should be distinguished from other symptom-similar diseases, such as Loeys-Dietz syndrome and Marfan syndrome. The syndrome of Marfan is characterized by heritable connective tissue lesion caused by the mutation of FBN1 gene among 90\% patients and involved in multiple organs including cardiac and valve (Baumgartner et al., 2010). Marfan syndrome has the higher risk of dissection and recurrent aneurysm than BAV with aortic dilation. For patients who have haploinsufficient FBN1 mutations, angiotensin II receptor inhibitor might reduce aortic root dilatation rate (Franken et al., 2015). $\beta$-Blockers is used to reduce the aortic dilation and improve the rate of survival (Engelfriet and Mulder, 2007). It has been suggested that patients need to have surgery when the maximal diameter of aortic root is more than $50 \mathrm{~mm}$ or other parts of the aorta $>50 \mathrm{~mm}$ or dilation is progressive according to ESC guidelines that about the management of congenital heart disease in adult patients. In some cases, although the aortic root diameter of patients is between 46 and $50 \mathrm{~mm}$, not reaching the criterion $50 \mathrm{~mm}$, they still need surgery because of progressive dilation $>2 \mathrm{~mm} /$ year (Baumgartner et al., 2010; Erbel et al., 2014a,b). And the JCS guideline recommend a more rigid criterion for surgery, maximal aortic diameter $\geq 45 \mathrm{~mm}$ or $>40 \mathrm{~mm}$ but with positive family history (Joint Working Group, 2013). When Marfan syndrome and pregnancy are cooccurrences in one women, it is suggested to make the root part of the aorta and ascending aorta replaced if the diameter $>40 \mathrm{~mm}$ according to AHA; however, the aortic root aneurysm $\geq 45 \mathrm{~mm}$ is the criterion for surgery according to ESC (Hiratzka et al., 2010). It is critical to perform the surgery with the experienced hands, which could reduce the risk of combining aortic valve and ascending aorta replacement (Gott et al., 1999). Valve-sparing operations or remodeling of the aortic root should be taken into consideration if the valves with normal anatomically (Kallenbach et al., 2007).

Few BAV patients were identified in Marfan syndrome patients. According to a study regarding association of Marfan syndrome and BAV, it is demonstrated that the association between the two disorders seems to cause a higher percentage of thoracic aortic aneurysm requiring surgical intervention (Nistri et al., 2012).

Loeys-Dietz syndrome, an autosomal-dominant connective tissue disorder, has different types based on gene mutations in the TGFBR1 (type 1), TGFBR2 (type 2), SMAD3 (type 3), and TGFB2 (type 4) (MacCarrick et al., 2014). Loeys-Dietz syndrome has the characteristics of rapidly progressive aortic aneurysm and aortic dissection and cerebral hemorrhages are major causes of death (Loeys et al., 2006). Hence, echocardiography monitoring is recommended as a useful diagnosis method to this syndrome (Van Hemelrijk et al., 2010). If some variations are observed including aortic root dimension $>40 \mathrm{~mm}$ or the expansion of aortic root $>0.5 \mathrm{~cm}$ over 1 year or the dimensions of the ascending aorta $>40 \mathrm{~mm}$ in adults and aortic annulus is 20$22 \mathrm{~mm}$ or the expansion of aorta $>0.5 \mathrm{~cm}$ over 1 year or severe craniofacial features or positive family history about aggressive aortic disease in children, it is time for surgical intervention (Renard et al., 2013). In American guideline, the aorta need to be repaired in these situations including BAV with Loeys-Dietz syndrome, the diameter of aorta $>4.2 \mathrm{~cm}$ by transoesophageal echocardiogram (internal diameter) with mutations in TGFBR1 or TGFBR2 or the external diameter $>4.4 \mathrm{~cm}$ by CT or MRI (Hiratzka et al., 2010). 


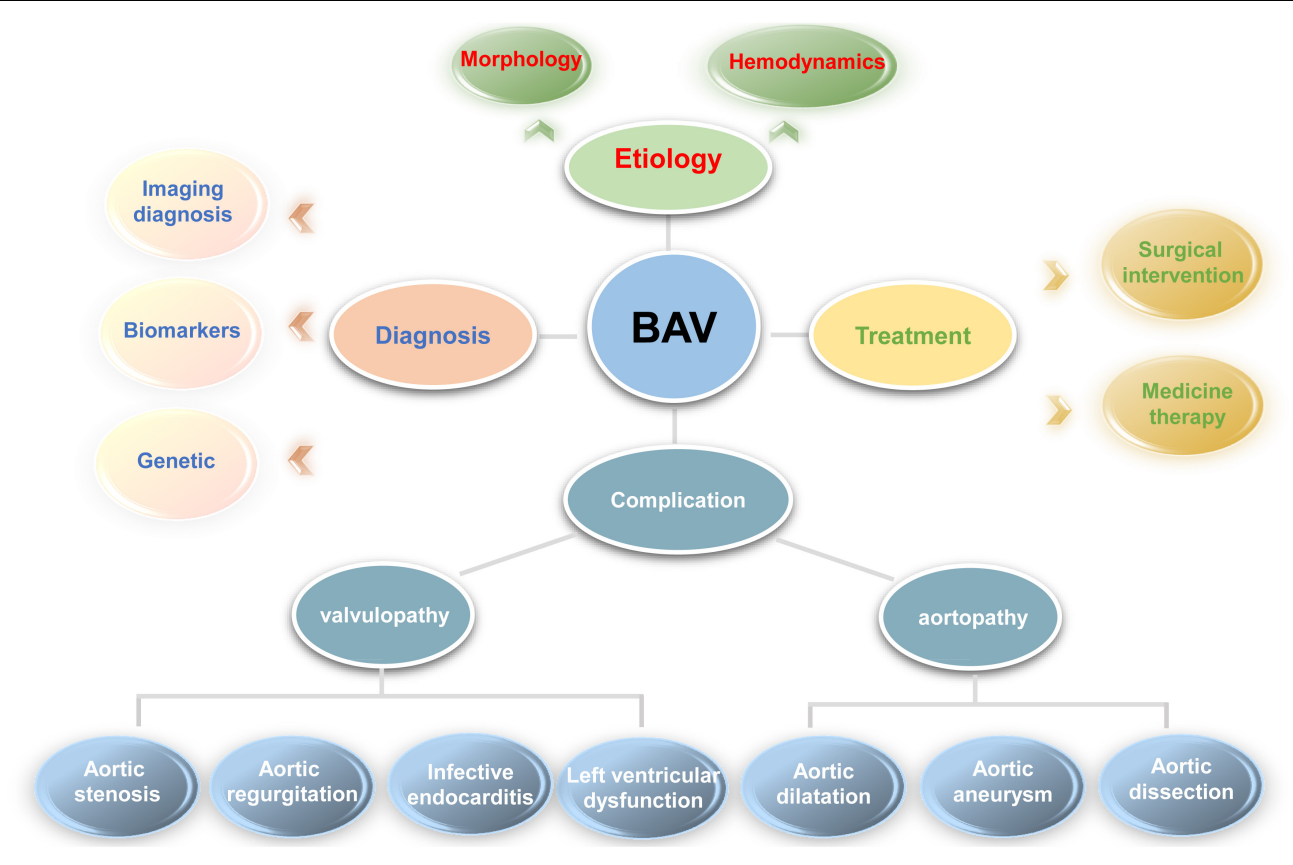

FIGURE 2 | For better understanding the problems involved in bicuspid aortic valve, a clear diagram was provided. In general, it includes the etiology (morphology and abnormal hemodynamics described in complication section), diagnosis (imaging, biomarker and genetic diagnosis), treatment (medicine and surgical treatment), and various complications involved in bicuspid aortic valve.

The surgery of valve-sparing seems to be prohibited in the situation of extensive calcification or dysfunction in BAV patients (Kasar et al., 2018). But the replacement surgery of valve-sparing aortic root could be recommended in experienced hands for children (Cleuziou et al., 2010). It is necessary to perform the aortic root repair surgery when the maximal dimension of aortic root reaches $40 \mathrm{~mm}$ in adults with LDS type 1 or 2 (MacCarrick et al., 2014). So far, there is no clear and comprehensive guideline to introduce the therapy on LoeysDietz syndrome.

\section{NEW TECHNIQUE: DEVELOPING MINIMALLY INVASIVE TECHNIQUE}

Many of the aortic valve replacements used clinically are not alive and ROSS procedure is an exception. In order to preserve the anatomical and functional integrity of the aortic root, ROSS procedure utilizes pulmonary autograft instead of lesions aortic valve (Mazine et al., 2018). ROSS procedure has good hemodynamic performance during activity and the lower gradient of normal aortic valve function at rest (Puranik et al., 2010). Patients who undergo ROSS surgery have a higher quality of life than patients who undergo mechanical valves (Zacek et al., 2016). ROSS has been improved in past several decades. At first, pulmonary autograft transplantation with the sub coronary and root replacement techniques translated into a full root replacement technique (Sievers et al., 2016). To prevent from postoperative expansion, prosthetic Dacron graft could be used to strengthening the pulmonary autograft (Carrel and Kadner, 2016). However, ROSS procedure has not been adopted worldwide with underlying reasons as operative risk and technical complexity. As a result, it increases possible failure of valves stability for long and complexity of the second intervention surgery (Reece et al., 2014). ROSS procedure is more suitable for younger patients or middle-aged $(<50$ years old) patients or prosthetic AVR in young patients with aortic insufficiency (Ouzounian et al., 2017). 85\% of BAV patients, whose median age is 40 years old, could be freedom from reoperation at 20 years with a follow-up of 9 years (Poh et al., 2018).

In spite of valve replacement is standard therapy now, BAV patients with normal cusps might be recommended to have valve repair (Zeeshan et al., 2018). For young patients, the aortic annulus does not match the adult-sized prosthesis and need normal root structure to grow. Hence, it is necessary to retain native aortic root in valve repair operation. Although cusp extension has no newer techniques, it seems unlikely to be avoided for young people as a part of aortic valve repair. Compared with BAV repair in children with median age 12.6 years by tricuspidization with cusp extension (TCE), the stability of valve function after ROSS procedure seems to be higher (McMullan et al., 2007). The other repair techniques used in the past have commissural suture, cusp procedures and aortic root procedures. The cusp procedures contain cusp resection, patching, commissurotomy, debridement and freemargin plication. The aortic root procedures include root remodeling, resuspension and reimplantation. Recently, figureof-8 suspensory sutures (Svensson) or Cabrol commissuroplasty are carried out in aortic valve repair. The point of suspensory 
sutures in Svensson operation is the lip of cusps at 3-4 mm above the commissure (Idrees et al., 2015). The latter is plication at center and 2 commissural stitches. Compare the outcomes of these techniques, Svensson technique has lower rate of reoperation and better durability for long, as well as valve resuspension, root repair and replacement (Svensson et al., 2014). However, some of cusp repair procedures such as commissuroplasty, commissural sutures and plication might be related to higher rate of reoperation (Jasinski et al., 2015). Kari technique could correct prolapse combined with valve-sparing aortic root replacement and cusp repair. $90 \%$ of the patients avoided reoperation at 6 years and 100\% avoided higher than grade 2 aortic regurgitation (Kari et al., 2013).

Ozaki technique was first reported in 2014 and use autologous pericardium to replace tricuspid. The pericardial cusp was excised at least $7 \mathrm{~cm} \times 8 \mathrm{~cm}$, and was sutured to the annulus (Ozaki et al., 2014). In 850 patients with average age of 71 years who have undergone Ozaki technique, $85.9 \%$ have the second operation, $4.2 \%$ have moderate $\mathrm{AR}$ and nobody had additional valve replacement. There was no conversion to a prosthetic valve replacement. The midterm outcome seemed to be satisfactory (Reuthebuch et al., 2018). For younger patients, Ozaki technique might have an advantage because it required only Aspirin, rather than antivitamin $\mathrm{K}$. The other one was that it did not need enlarge aortic root for patients with small annulus. Given the benefits of Ozaki technique, minimally Invasive Ozaki's Procedure was carried out in nine patients. First, the minimally invasive procedure could provide clear surgical field by smaller incision to collect pericardium and reduce damage to the heart or risk of hemostasis. In addition, patients could be freedom from ventilation earlier, reduce ICU and hospital stay after operation. Thus, upper ministernotomy combined with Ozaki procedure might be a feasible approach instead of full sternotomy (Nguyen et al., 2018). However, Ozaki technique or combined ministernotomy require longer follow-up outcomes in young adults.

\section{FUTURE DIRECTIONS}

Bicuspid aortic valve is a general geneogenous heart defects and burden from BAV is more significant than other congenital cardiac lesions around the word. Despite many emerging studies focus on the pathogenesis, diagnosis and treatment of BAV as shown in Figure 2, our understanding of the disease is still incomplete and many questions remain need to be illuminated in future studies.

Gene mutations polymorphism and aberrant changes in hemodynamics have been thought to be the two main aspects of BAV pathogenesis. Although it has been reported that

\section{REFERENCES}

Allen, B. D., van Ooij, P., Barker, A. J., Carr, M., Gabbour, M., Schnell, S., et al. (2015). Thoracic aorta 3D hemodynamics in pediatric and young adult patients with bicuspid aortic valve. J. Magn. Reson. Imaging 42, 954-963. doi: 10.1002/ jmri.24847 many genes and cellular signaling pathway were involved in malformations of valves, none has been confirmed to play central role. This restricts the clinical translational applications of research findings to patients timely. Hemodynamics which is affected by malformations of the valves, might not be reversed by preventive surgical intervention. To date, it is necessary to perfume early biomarkers test and multiple imaging diagnosis including ultrasound, cardiac CT and 4D MRI. Although given the weight of evidence about aberrant biomarkers in BAV patients, it still needs to be clarified the importance of these biomarkers when they are appeared in patients' samples. Besides, the relationship between these biomarkers and severity or prognosis of BAV need to be explored further. Therefore, specificity and sensibility of biomarkers are relative insufficiency, and could not provide accurate information for doctors. Combined imaging diagnosis seems to be the only effective method to evaluate valve morphology, function, hemodynamics and complications, which present evidence for timely surgical intervention.

Although medicine treatment has not achieved obvious effect in BAV patients, gene targeted delivery or therapy might be a promising treatment to prevent BAV and its complications according to widely genetic research. So far, surgical intervention is the only efficient way in the management of patients. The threshold of surgery, aortic diameter, has been modified repeatedly in the international guidelines, but it is inadequate to draw a perfect heal scheme. Although aortic valve replacement is the major surgical therapy recently, other surgical techniques still need to be explored and tried. It would be better if they could be combined with invasive techniques in the future. Since the development of BAV is affected by multiple factors as mentioned before, optimal surgical intervention and comprehensive treatment options should be individualized to the patients in the future.

\section{AUTHOR CONTRIBUTIONS}

TL performed literature review and drafted the article. MX, QL, YL, LF, and LZ contributed to the revision and edition of the manuscript. WD collected the articles. JW revised and critically appraised the manuscript for intellectual content. All authors read and approved the final manuscript.

\section{FUNDING}

This work was supported by the grant from the National Natural Science Foundation of China (81771851 and 81530056).

Ambale-Venkatesh, B., and Lima, J. A. (2015). Cardiac MRI: a central prognostic tool in myocardial fibrosis. Nat. Rev. Cardiol. 12, 18-29. doi: 10.1038/nrcardio. 2014.159

Arangalage, D., Laredo, M., Ou, P., Brochet, E., Cimadevilla, C., EnriquezSarano, M., et al. (2018). Anatomic characterization of the aortic root in patients with bicuspid and tricuspid aortic valve stenosis: does fusion 
of doppler-echocardiography and computed tomography resolve discordant severity grading? JACC Cardiovasc. Imaging doi: 10.1016/j.jcmg.2018.04.013 [Epub ahead of print].

Balistreri, C. R., Crapanzano, F., Schirone, L., Allegra, A., Pisano, C., Ruvolo, G., et al. (2018). Deregulation of Notch1 pathway and circulating endothelial progenitor cell (EPC) number in patients with bicuspid aortic valve with and without ascending aorta aneurysm. Sci. Rep. 8:13834. doi: 10.1038/s41598-01832170-2

Balmer, C., Beghetti, M., Fasnacht, M., Friedli, B., and Arbenz, U. (2004). Balloon aortic valvoplasty in paediatric patients: progressive aortic regurgitation is common. Heart 90, 77-81. doi: 10.1136/heart.90.1.77

Barker, A. J., Markl, M., and Fedak, P. (2018). Assessing wall stresses in bicuspid aortic valve-associated aortopathy: forecasting the perfect storm? J. Thorac. Cardiovasc. Surg. 156, 471-472. doi: 10.1016/j.jtcvs.2018.03.092

Baumgartner, H., Bonhoeffer, P., De Groot, N. M., de Haan, F., Deanfield, J. E., Galie, N., et al. (2010). ESC Guidelines for the management of grown-up congenital heart disease (new version 2010). Eur. Heart J. 31, 2915-2957. doi: 10.1093/eurheartj/ehq249

Bavaria, J. E., Komlo, C. M., Rhode, T., and Vallabhajosyula, P. (2013). Can the bicuspid aortic valve be spared? The con position, with caveats and nuances. Tex. Heart Inst. J. 40, 544-546. doi: < doi>

Ben-Dor, I., and Stewart, A. (2017). A cautionary tale of 2 leaflets: TAVR in bicuspid aortic valve stenosis. J. Am. Coll. Cardiol. 69, 2590-2591. doi: 10.1016/j.jacc. 2017.03.573

Bhave, N. M., and Eagle, K. A. (2018). "Much More Than a Tube": the aneurysmal ascending aorta as a dynamic entity. JACC Cardiovasc. Imaging doi: 10.1016/j. jcmg.2018.04.006 [Epub ahead of print].

Bissell, M. M., Hess, A. T., Biasiolli, L., Glaze, S. J., Loudon, M., Pitcher, A., et al. (2013). Aortic dilation in bicuspid aortic valve disease: flow pattern is a major contributor and differs with valve fusion type. Circ. Cardiovasc. Imaging 6, 499-507. doi: 10.1161/CIRCIMAGING.113.000528

Bjorck, H. M., Du, L., Pulignani, S., Paloschi, V., Lundstromer, K., Kostina, A. S., et al. (2018). Altered DNA methylation indicates an oscillatory flow mediated epithelial-to-mesenchymal transition signature in ascending aorta of patients with bicuspid aortic valve. Sci. Rep. 8:2777. doi: 10.1038/s41598-018-20642-4

Boe, B. A., Zampi, J. D., Kennedy, K. F., Jayaram, N., Porras, D., Foerster, S. R., et al. (2017). Acute success of balloon aortic valvuloplasty in the current Era: a national cardiovascular data registry study. JACC Cardiovasc. Interv. 10, 1717-1726. doi: 10.1016/j.jcin.2017.08.001

Bollache, E., Guzzardi, D. G., Sattari, S., Olsen, K. E., Di Martino, E. S., Malaisrie, S. C., et al. (2018). Aortic valve-mediated wall shear stress is heterogeneous and predicts regional aortic elastic fiber thinning in bicuspid aortic valve-associated aortopathy. J. Thorac. Cardiovasc. Surg. 156, 2112-2120.e2. doi: 10.1016/j.jtcvs. 2018.05.095

Boonyasirinant, T., Rajiah, P., and Flamm, S. D. (2018). Abnormal aortic stiffness in patients with bicuspid aortic valve: phenotypic variation determined by magnetic resonance imaging. Int. J. Cardiovasc. Imaging doi: 10.1007/s10554018-1433-y [Epub ahead of print].

Braverman, A. C., Guven, H., Beardslee, M. A., Makan, M., Kates, A. M., and Moon, M. R. (2005). The bicuspid aortic valve. Curr. Probl. Cardiol. 30, 470-522. doi: 10.1016/j.cpcardiol.2005.06.002

Broch, K., de Marchi, S. F., Massey, R., Hisdal, J., Aakhus, S., Gullestad, L., et al. (2017). Left ventricular contraction pattern in chronic aortic regurgitation and preserved ejection fraction: simultaneous stress-strain analysis by threedimensional echocardiography. J. Am. Soc. Echocardiogr. 30, 422-430. doi: 10.1016/j.echo.2016.11.012

Carrel, T., and Kadner, A. (2016). Long-term clinical and imaging follow-up after reinforced pulmonary autograft ross procedure. Semin. Thorac. Cardiovasc. Surg. Pediatr. Card. Surg. Annu. 19, 59-62. doi: 10.1053/j.pcsu.2015.11.005

Chamberland, C. R., Sugeng, L., Abraham, S., Li, F., and Weismann, C. G. (2015). Three-dimensional evaluation of aortic valve annular shape in children with bicuspid aortic valves and/or aortic coarctation compared with controls. Am. J. Cardiol. 116, 1411-1417. doi: 10.1016/j.amjcard.2015.07.063

Chambers, J. B. (2018). Antibiotic prophylaxis against infective endocarditis: widening the net? J. Am. Coll. Cardiol. 71, 2741-2743. doi: 10.1016/j.jacc.2018. 04.021

Chen, J., Lu, S., Hu, K., Yang, Z., Pan, S., Hong, T., et al. (2017). Clinical characteristics and surgical treatment of infective endocarditis with bicuspid aortic valve. Int. Heart J. 58, 220-224. doi: 10.1536/ihj. $16-284$

Clavel, M. A., Malouf, J., Messika-Zeitoun, D., Araoz, P. A., Michelena, H. I., and Enriquez-Sarano, M. (2015). Aortic valve area calculation in aortic stenosis by CT and Doppler echocardiography. JACC Cardiovasc. Imaging 8, 248-257. doi: 10.1016/j.jcmg.2015.01.009

Cleuziou, J., Eichinger, W. B., Schreiber, C., and Lange, R. (2010). Aortic root replacement with re-implantation technique in an infant with Loeys-Dietz syndrome and a bicuspid aortic valve. Pediatr. Cardiol. 31, 117-119. doi: 10. 1007/s00246-009-9541-z

Cotrufo, M., Della, C. A., De Santo, L. S., Quarto, C., De Feo, M., Romano, G., et al. (2005). Different patterns of extracellular matrix protein expression in the convexity and the concavity of the dilated aorta with bicuspid aortic valve: preliminary results. J. Thorac. Cardiovasc. Surg. 130, 504-511. doi: 10.1016/j. jtcvs.2005.01.016

Dargis, N., Lamontagne, M., Gaudreault, N., Sbarra, L., Henry, C., Pibarot, P., et al. (2016). Identification of gender-specific genetic variants in patients with bicuspid aortic valve. Am. J. Cardiol. 117, 420-426. doi: 10.1016/j.amjcard.2015. 10.058

David, T. E. (2016). Aortic valve sparing in different aortic valve and aortic root conditions. J. Am. Coll. Cardiol. 68, 654-664. doi: 10.1016/j.jacc.2016.04.062

de Kerchove, L., Vismara, R., Mangini, A., Fiore, G. B., Price, J., and Noirhomme, P. (2012). In vitro comparison of three techniques for ventriculo-aortic junction annuloplasty. Eur. J. Cardiothorac. Surg. 41, 1117-1123; discussion 1123-1124. doi: 10.1093/ejcts/ezr237

Detaint, D., Michelena, H. I., Nkomo, V. T., Vahanian, A., Jondeau, G., and Sarano, M. E. (2014). Aortic dilatation patterns and rates in adults with bicuspid aortic valves: a comparative study with Marfan syndrome and degenerative aortopathy. Heart 100, 126-134. doi: 10.1136/heartjnl-2013-304920

Disha, K., Dubslaff, G., Rouman, M., Fey, B., Borger, M. A., Barker, A. J., et al. (2017). Evidence of subannular and left ventricular morphological differences in patients with bicuspid versus tricuspid aortic valve stenosis: magnetic resonance imaging-based analysis. Interact. Cardiovasc. Thorac. Surg. 24, 369-376. doi: 10.1093/icvts/ivw363

Donati, F., Myerson, S., Bissell, M. M., Smith, N. P., Neubauer, S., Monaghan, M. J., et al. (2017). Beyond Bernoulli: improving the accuracy and precision of noninvasive estimation of peak pressure drops. Circ. Cardiovasc. Imaging 10:e005207. doi: 10.1161/CIRCIMAGING.116.005207

Du, J., Zheng, R., Xiao, F., Zhang, S., He, K., Zhang, J., et al. (2017). Downregulated MicroRNA-195 in the bicuspid aortic valve promotes calcification of valve interstitial cells via targeting SMAD7. Cell. Physiol. Biochem. 44, 884-896. doi: $10.1159 / 000485356$

Dweck, M. R., Joshi, S., Murigu, T., Gulati, A., Alpendurada, F., Jabbour, A., et al. (2012). Left ventricular remodeling and hypertrophy in patients with aortic stenosis: insights from cardiovascular magnetic resonance. J. Cardiovasc. Magn. Reson. 14:50. doi: 10.1186/1532-429X-14-50

Dyverfeldt, P., Bissell, M., Barker, A. J., Bolger, A. F., Carlhall, C. J., Ebbers, T., et al. (2015). $4 \mathrm{D}$ flow cardiovascular magnetic resonance consensus statement. J. Cardiovasc. Magn. Reson. 17:72. doi: 10.1186/s12968-015-0174-5

El, K. G., Glineur, D., Rubay, J., Verhelst, R., D’Acoz, Y., Poncelet, A., et al. (2005). Functional classification of aortic root/valve abnormalities and their correlation with etiologies and surgical procedures. Curr. Opin. Cardiol. 20, 115-121. doi: 10.1097/01.hco.0000153951.31887.a6

Engelfriet, P., and Mulder, B. (2007). Is there benefit of beta-blocking agents in the treatment of patients with the Marfan syndrome? Int. J. Cardiol. 114, 300-302. doi: 10.1016/j.ijcard.2006.01.025

Erbel, R., Aboyans, V., Boileau, C., Bossone, E., Bartolomeo, R. D., Eggebrecht, H., et al. (2014a). 2014 ESC Guidelines on the diagnosis and treatment of aortic diseases: document covering acute and chronic aortic diseases of the thoracic and abdominal aorta of the adult. The task force for the diagnosis and treatment of aortic diseases of the European society of cardiology (ESC). Eur. Heart J. 35, 2873-2926. doi: 10.1093/eurheartj/ehu281

Erbel, R., Aboyans, V., Boileau, C., Bossone, E., Di Bartolomeo, R., Eggebrecht, H., et al. (2014b). [2014 ESC Guidelines on the diagnosis and treatment of aortic diseases]. Kardiol. Pol. 72, 1169-1252. doi: 10.5603/KP.2014.0225

Esaki, J., Leshnower, B. G., Binongo, J. N., Lasanajak, Y., McPherson, L., Halkos, M. E., et al. (2017). Clinical outcomes of the David V valve-sparing root replacement compared with bioprosthetic valve-conduits for aortic root 
aneurysms. Ann. Thorac. Surg. 103, 1824-1832. doi: 10.1016/j.athoracsur.2016. 09.055

Evangelista, A. (2016). Familial nonsyndromic thoracic aortic aneurysms: unraveling the mystery and defining long-term outcome. J. Am. Coll. Cardiol. 67, 627-629. doi: 10.1016/j.jacc.2015.11.038

Farag, E. S., van Ooij, P., Planken, R. N., Dukker, K., de Heer, F., Bouma, B. J., et al. (2018). Aortic valve stenosis and aortic diameters determine the extent of increased wall shear stress in bicuspid aortic valve disease. J. Magn. Reson. Imaging 48, 522-530. doi: 10.1002/jmri.25956

Ferrara, A., Totaro, P., Morganti, S., and Auricchio, F. (2018). Effects of clinicopathological risk factors on in-vitro mechanical properties of human dilated ascending aorta. J. Mech. Behav. Biomed. Mater. 77, 1-11. doi: 10.1016/j.jmbbm. 2017.08.032

Forte, A., Bancone, C., Cobellis, G., Buonocore, M., Santarpino, G., Fischlein, T., et al. (2017). A possible early biomarker for bicuspid aortopathy: circulating transforming growth factor beta-1 to soluble Endoglin ratio. Circ. Res. 120, 1800-1811. doi: 10.1161/CIRCRESAHA.117.310833

Franken, R., den Hartog, A. W., Radonic, T., Micha, D., Maugeri, A., van Dijk, F. S., et al. (2015). Beneficial outcome of losartan therapy depends on type of FBN1 mutation in Marfan syndrome. Circ. Cardiovasc. Genet. 8, 383-388. doi: 10.1161/CIRCGENETICS.114.000950

Freeze, S. L., Landis, B. J., Ware, S. M., and Helm, B. M. (2016). Bicuspid aortic valve: a review with recommendations for genetic counseling. J. Genet. Couns. 25, 1171-1178. doi: 10.1007/s10897-016-0002-6

Gamaza-Chulian, S., Diaz-Retamino, E., Camacho-Freire, S., Ruiz-Fernandez, D., Gutierrez-Barrios, A., and Oneto-Otero, J. (2017). Acceleration time and ratio of acceleration time to ejection time in aortic stenosis: new echocardiographic diagnostic parameters. J. Am. Soc. Echocardiogr. 30, 947-955. doi: 10.1016/j. echo.2017.06.001

Gaztanaga, J., Paruchuri, V., Elias, E., Wilner, J., Islam, S., Sawit, S., et al. (2016). Prognostic value of late gadolinium enhancement in nonischemic cardiomyopathy. Am. J. Cardiol. 118, 1063-1068. doi: 10.1016/j.amjcard.2016. 06.059

Gharibeh, L., Komati, H., Bosse, Y., Boodhwani, M., Heydarpour, M., Fortier, M., et al. (2018). GATA6 regulates aortic valve remodeling and its haploinsufficiency leads to RL-type bicuspid aortic valve. Circulation 138, 1025-1038. doi: 10.1161/ CIRCULATIONAHA.117.029506

Girdauskas, E., Disha, K., Espinoza, A., Misfeld, M., Reichenspurner, H., Borger, M. A., et al. (2017). Mitral regurgitation after previous aortic valve surgery for bicuspid aortic valve insufficiency. J. Cardiovasc. Surg. 58, 473-480. doi: < doi>

Giusti, B., Sticchi, E., De Cario, R., Magi, A., Nistri, S., and Pepe, G. (2017). Genetic bases of bicuspid aortic valve: the contribution of traditional and highthroughput sequencing approaches on research and diagnosis. Front. Physiol. 8:612. doi: 10.3389/fphys.2017.00612

Gott, V. L., Greene, P. S., Alejo, D. E., Cameron, D. E., Naftel, D. C., Miller, D. C., et al. (1999). Replacement of the aortic root in patients with Marfan's syndrome. N. Engl. J. Med. 340, 1307-1313. doi: 10.1056/NEJM199904293401702

Goudot, G., Mirault, T., Rossi, A., Zarka, S., Albuisson, J., Achouh, P., et al. (2018). Segmental aortic stiffness in patients with bicuspid aortic valve compared with first-degree relatives. Heart 105, 130-136. doi: 10.1136/heartjnl-2018-313232

Gu, J., Chen, Y., Zhang, H., Meng, W., Hu, J., and Zhang, E. (2014). Multimodality images of a giant blood cyst originating from the bicuspid aortic valve. Circulation 130, e165-e166. doi: 10.1161/CIRCULATIONAHA.114.012465

Guala, A., Rodriguez-Palomares, J., Dux-Santoy, L., Teixido-Tura, G., Maldonado, G., Galian, L., et al. (2018). Influence of aortic dilation on the regional aortic stiffness of bicuspid aortic valve assessed by 4dimensional flow cardiac magnetic resonance: comparison with Marfan syndrome and degenerative aortic aneurysm. JACC Cardiovasc. Imaging doi: 10.1016/j.jcmg.2018.03.017 [Epub ahead of print].

Helgadottir, A., Thorleifsson, G., Gretarsdottir, S., Stefansson, O. A., Tragante, V., Thorolfsdottir, R. B., et al. (2018). Genome-wide analysis yields new loci associating with aortic valve stenosis. Nat. Commun. 9:987. doi: 10.1038/ s41467-018-03252-6

Hirata, Y., Aoki, H., Shojima, T., Takagi, K., Takaseya, T., Akasu, K., et al. (2018). Activation of the AKT pathway in the ascending aorta with bicuspid aortic valve. Circ. J. 82, 2485-2492. doi: 10.1253/circj.CJ-17-1465

Hiratzka, L. F., Bakris, G. L., Beckman, J. A., Bersin, R. M., Carr, V. F., Casey, D. J., et al. (2010). 2010 ACCF/AHA/AATS/ACR/ASA/SCA/SCAI/SIR/STS/SVM guidelines for the diagnosis and management of patients with thoracic aortic disease: executive summary. A report of the American College of Cardiology Foundation/American Heart Association Task Force on Practice Guidelines, American Association for Thoracic Surgery, American College of Radiology, American Stroke Association, Society of Cardiovascular Anesthesiologists, Society for Cardiovascular Angiography and Interventions, Society of Interventional Radiology, Society of Thoracic Surgeons, and Society for Vascular Medicine. Catheter. Cardiovasc. Interv. 76, E43-E86. doi: 10.1002/ ccd. 22537

Hiratzka, L. F., Creager, M. A., Isselbacher, E. M., Svensson, L. G., Nishimura, R. A., Bonow, R. O., et al. (2016). Surgery for aortic dilatation in patients with bicuspid aortic valves: a statement of clarification from the American college of cardiology/American heart association task force on clinical practice guidelines. Circulation 133, 680-686. doi: 10.1161/CIR.0000000000000331

Hui, S. K., Fan, C. S., Christie, S., Feindel, C. M., David, T. E., and Ouzounian, M. (2018). The aortic root does not dilate over time after replacement of the aortic valve and ascending aorta in patients with bicuspid or tricuspid aortic valves. J. Thorac. Cardiovasc. Surg. 156, 5-13. doi: 10.1016/j.jtcvs.2018.02.094

Idrees, J. J., Roselli, E. E., Arafat, A., Johnston, D. R., Svensson, L. G., Sabik, J. R., et al. (2015). Outcomes after repair or replacement of dysfunctional quadricuspid aortic valve. J. Thorac. Cardiovasc. Surg. 150, 79-82. doi: 10.1016/ j.jtcvs.2015.03.019

Iung, B. (2015). New ESC guidelines: aortic disease. Heart 101, 421-423. doi: 10.1136/heartjnl-2014-306777

Jasinski, M. J., Gocol, R., Malinowski, M., Hudziak, D., Duraj, P., and Deja, M. A. (2015). Predictors of early and medium-term outcome of 200 consecutive aortic valve and root repairs. J. Thorac. Cardiovasc. Surg. 149, 123-129. doi: 10.1016/j. jtcvs.2014.08.057

Jassal, D. S., Bhagirath, K. M., Tam, J. W., Sochowski, R. A., Dumesnil, J. G., Giannoccaro, P. J., et al. (2010). Association of Bicuspid aortic valve morphology and aortic root dimensions: a substudy of the aortic stenosis progression observation measuring effects of rosuvastatin (ASTRONOMER) study. Echocardiography 27, 174-179. doi: 10.1111/j.1540-8175.2009.00993.x

Jilaihawi, H., Chen, M., Webb, J., Himbert, D., Ruiz, C. E., Rodes-Cabau, J., et al. (2016). A bicuspid aortic valve imaging classification for the TAVR Era. JACC Cardiovasc. Imaging 9, 1145-1158. doi: 10.1016/j.jcmg.2015.12.022

Jilaihawi, H., Kashif, M., Fontana, G., Furugen, A., Shiota, T., Friede, G., et al. (2012). Cross-sectional computed tomographic assessment improves accuracy of aortic annular sizing for transcatheter aortic valve replacement and reduces the incidence of paravalvular aortic regurgitation. J. Am. Coll. Cardiol. 59, 1275-1286. doi: 10.1016/j.jacc.2011.11.045

Joint Working Group (2013). Guidelines for diagnosis and treatment of aortic aneurysm and aortic dissection (JCS 2011): digest version. Circ. J. 77, 789-828. doi: 10.1253/circj.CJ-66-0057

Kallenbach, K., Baraki, H., Khaladj, N., Kamiya, H., Hagl, C., Haverich, A., et al. (2007). Aortic valve-sparing operation in Marfan syndrome: what do we know after a decade? Ann. Thorac. Surg. 83, S764-S768. doi: 10.1016/j.athoracsur. 2006.10.097

Kari, F. A., Liang, D. H., Kvitting, J. P., Stephens, E. H., Mitchell, R. S., Fischbein, M. P., et al. (2013). Tirone David valve-sparing aortic root replacement and cusp repair for bicuspid aortic valve disease. J. Thorac. Cardiovasc. Surg. 145, S35-S40. doi: 10.1016/j.jtcvs.2012.11.043

Kasar, T., Gezdirici, A., Ayyildiz, P., Haydin, S., and Guzeltas, A. (2018). Valvesparing aortic root replacement in Loeys-Dietz syndrome and a novel mutation in TGFBR2. Anatol. J. Cardiol. 19, 74-77. doi: 10.14744/AnatolJCardiol.2017. 7911

Kerstjens-Frederikse, W. S., van de Laar, I. M., Vos, Y. J., Verhagen, J. M., Berger, R. M., and Lichtenbelt, K. D. (2016). Cardiovascular malformations caused by NOTCH1 mutations do not keep left: data on 428 probands with left-sided CHD and their families. Genet. Med. 18, 914-923. doi: 10.1038/gim.2015.193

Khoo, C., Cheung, C., and Jue, J. (2013). Patterns of aortic dilatation in bicuspid aortic valve-associated aortopathy. J. Am. Soc. Echocardiogr. 26, 600-605. doi: 10.1016/j.echo.2013.02.017

Kim, J. B., Spotnitz, M., Lindsay, M. E., MacGillivray, T. E., Isselbacher, E. M., and Sundt, T. R. (2016). Risk of aortic dissection in the moderately dilated ascending aorta. J. Am. Coll. Cardiol. 68, 1209-1219. doi: 10.1016/j.jacc.2016.06.025

Knirsch, W., Berger, F., Harpes, P., and Kretschmar, O. (2008). Balloon valvuloplasty of aortic valve stenosis in childhood: early and medium 
term results. Clin. Res. Cardiol. 97, 587-593. doi: 10.1007/s00392-0080655-8

Komiya, T. (2015). Aortic valve repair update. Gen. Thorac. Cardiovasc. Surg. 63, 309-319. doi: 10.1007/s11748-015-0523-1

Kong, W., Regeer, M. V., Poh, K. K., Yip, J. W., van Rosendael, P. J., Yeo, T. C., et al. (2018). Inter-ethnic differences in valve morphology, valvular dysfunction, and aortopathy between Asian and European patients with bicuspid aortic valve. Eur. Heart J. 39, 1308-1313. doi: 10.1093/eurheartj/ehx562

Kong, W. K., Delgado, V., Poh, K. K., Regeer, M. V., Ng, A. C., McCormack, L., et al. (2017). Prognostic implications of raphe in bicuspid aortic valve anatomy. JAMA Cardiol. 2, 285-292. doi: 10.1001/jamacardio.2016.5228

Krieger, E. V., and Hung, J. (2018). Bicuspid aortic valve type: it takes two. Heart 104, 544-545. doi: 10.1136/heartjnl-2017-312133

Laforest, B., Andelfinger, G., and Nemer, M. (2011). Loss of Gata5 in mice leads to bicuspid aortic valve. J. Clin. Invest. 121, 2876-2887. doi: 10.1172/JCI4 4555

Lee, S. Y., Shim, C. Y., Hong, G. R., Seo, J., Cho, I., Cho, I. J., et al. (2015). Association of aortic phenotypes and mechanical function with left ventricular diastolic function in subjects with normally functioning bicuspid aortic valves and comparison to subjects with tricuspid aortic valves. Am. J. Cardiol. 116, 1547-1554. doi: 10.1016/j.amjcard.2015.08.017

Lehoux, S., and Tedgui, A. (2003). Cellular mechanics and gene expression in blood vessels. J. Biomech. 36, 631-643. doi: 10.1016/S0021-9290(02)00441-4

Li, Y., Wei, X., Zhao, Z., Liao, Y., He, J., Xiong, T., et al. (2017). Prevalence and complications of bicuspid aortic valve in Chinese according to echocardiographic database. Am. J. Cardiol. 120, 287-291. doi: 10.1016/j. amjcard.2017.04.025

Liu, X., He, Y., Zhu, Q., Gao, F., He, W., Yu, L., et al. (2018). Supra-annular structure assessment for self-expanding transcatheter heart valve size selection in patients with bicuspid aortic valve. Catheter. Cardiovasc. Interv. 91, 986-994. doi: $10.1002 /$ ccd.27467

Lluri, G., Renella, P., Finn, J. P., Vorobiof, G., Aboulhosn, J., and Deb, A. (2017) Prognostic significance of left ventricular fibrosis in patients with congenital bicuspid aortic valve. Am. J. Cardiol. 120, 1176-1179. doi: 10.1016/j.amjcard. 2017.06.060

Loeys, B. L., Schwarze, U., Holm, T., Callewaert, B. L., Thomas, G. H., Pannu, H., et al. (2006). Aneurysm syndromes caused by mutations in the TGF-beta receptor. N. Engl. J. Med. 355, 788-798. doi: 10.1056/NEJMoa055695

Longobardo, L., Jain, R., Carerj, S., Zito, C., and Khandheria, B. K. (2016). Bicuspid aortic valve: unlocking the morphogenetic puzzle. Am. J. Med. 129, 796-805. doi: 10.1016/j.amjmed.2016.03.009

MacCarrick, G., Black, J. R., Bowdin, S., El-Hamamsy, I., Frischmeyer-Guerrerio, P. A., and Guerrerio, A. L. (2014). Loeys-Dietz syndrome: a primer for diagnosis and management. Genet. Med. 16, 576-587. doi: 10.1038/gim.2014.11

MacGrogan, D., D’Amato, G., Travisano, S., Martinez-Poveda, B., Luxan, G., Del, M. G., et al. (2016). Sequential ligand-dependent notch signaling activation regulates valve primordium formation and morphogenesis. Circ. Res. 118, 1480-1497. doi: 10.1161/CIRCRESAHA.115.308077

Mart, C. R., and McNerny, B. E. (2013). Shape of the dilated aorta in children with bicuspid aortic valve. Ann. Pediatr. Cardiol. 6, 126-131. doi: 10.4103/09742069.115253

Masri, A., Kalahasti, V., Alkharabsheh, S., Svensson, L. G., Sabik, J. F., Roselli, E. E., et al. (2016). Characteristics and long-term outcomes of contemporary patients with bicuspid aortic valves. J. Thorac. Cardiovasc. Surg. 151, 1650-1659. doi: 10.1016/j.jtcvs.2015.12.019

Masri, A., Kalahasti, V., Svensson, L. G., Alashi, A., Schoenhagen, P., Roselli, E. E., et al. (2017a). Aortic cross-sectional area/height ratio and outcomes in patients with bicuspid aortic valve and a dilated ascending aorta. Circ. Cardiovasc. Imaging 10:e6249. doi: 10.1161/CIRCIMAGING.116.006249

Masri, A., Svensson, L. G., Griffin, B. P., and Desai, M. Y. (2017b). Contemporary natural history of bicuspid aortic valve disease: a systematic review. Heart 103, 1323-1330. doi: 10.1136/heartjnl-2016-309916

Mazine, A., El-Hamamsy, I., Verma, S., Peterson, M. D., Bonow, R. O., Yacoub, M. H., et al. (2018). Ross procedure in adults for cardiologists and cardiac surgeons: JACC state-of-the-art review. J. Am. Coll. Cardiol. 72, 2761-2777. doi: $10.1016 /$ j.jacc.2018.08.2200

McMullan, D. M., Oppido, G., Davies, B., Kawahira, Y., Cochrane, A. D., D’Udekem, D. Y., et al. (2007). Surgical strategy for the bicuspid aortic valve: tricuspidization with cusp extension versus pulmonary autograft. J. Thorac. Cardiovasc. Surg. 134, 90-98. doi: 10.1016/j.jtcvs.2007.01.054

Merkx, R., Duijnhouwer, A. L., Vink, E., Roos-Hesselink, J. W., and Schokking, M. (2017). Aortic diameter growth in children with a bicuspid aortic valve. Am. J. Cardiol. 120, 131-136. doi: 10.1016/j.amjcard.2017.03.245

Michelena, H. I., Khanna, A. D., Mahoney, D., Margaryan, E., Topilsky, Y., Suri, R. M., et al. (2011). Incidence of aortic complications in patients with bicuspid aortic valves. JAMA 306, 1104-1112. doi: 10.1001/jama.2011.1286

Michelena, H. I., Prakash, S. K., Della, C. A., Bissell, M. M., Anavekar, N., Mathieu, P., et al. (2014). Bicuspid aortic valve: identifying knowledge gaps and rising to the challenge from the International Bicuspid Aortic Valve Consortium (BAVCon). Circulation 129, 2691-2704. doi: 10.1161/CIRCULATIONAHA. 113.007851

Mojazi-Amiri, H., and Pai, R. G. (2013). Prognostic value of cardiac magnetic resonance imaging in patients with aortic regurgitation. Future Cardiol. 9, 9-12. doi: $10.2217 /$ fca. 12.79

Mylotte, D., Lefevre, T., Sondergaard, L., Watanabe, Y., Modine, T., Dvir, D., et al. (2014). Transcatheter aortic valve replacement in bicuspid aortic valve disease. J. Am. Coll. Cardiol. 64, 2330-2339. doi: 10.1016/j.jacc.2014.09.039

Nataatmadja, M., West, M., West, J., Summers, K., Walker, P., Nagata, M., et al. (2003). Abnormal extracellular matrix protein transport associated with increased apoptosis of vascular smooth muscle cells in Marfan syndrome and bicuspid aortic valve thoracic aortic aneurysm. Circulation 108(Suppl. 1), I329-I334. doi: 10.1161/01.cir.0000087660.82721.15

Navarra, E., El, K. G., Glineur, D., Boodhwani, M., Van Dyck, M., Vanoverschelde, J. L., et al. (2013). Effect of annulus dimension and annuloplasty on bicuspid aortic valve repair. Eur. J. Cardiothorac. Surg. 44, 316-322; discussion 322-323. doi: 10.1093/ejcts/ezt045

Nawaytou, O., Mastrobuoni, S., de Kerchove, L., Baert, J., Boodhwani, M., and El, K. G. (2018). Deep circumferential annuloplasty as an adjunct to repair regurgitant bicuspid aortic valves with a dilated annulus. J. Thorac. Cardiovasc. Surg. 156, 590-597. doi: 10.1016/j.jtcvs.2018.03.110

Ng, A. C., Delgado, V., Bertini, M., Antoni, M. L., van Bommel, R. J., van Rijnsoever, E. P., et al. (2011). Alterations in multidirectional myocardial functions in patients with aortic stenosis and preserved ejection fraction: a two-dimensional speckle tracking analysis. Eur. Heart J. 32, 1542-1550. doi: 10.1093/eurheartj/ehr084

Nguyen, D. H., Vo, A. T., Le, K. M., Vu, T. T., Nguyen, T. T., Vu, T. T., et al. (2018). Minimally invasive Ozaki procedure in aortic valve disease: the preliminary results. Innovations 13, 332-337. doi: 10.1097/IMI.0000000000000556

Nishimura, R. A., Otto, C. M., Bonow, R. O., Carabello, B. A., Erwin, J. R., Fleisher, L. A., et al. (2017). 2017 AHA/ACC focused update of the 2014 AHA/ACC guideline for the management of patients with valvular heart disease: a report of the American college of cardiology/American heart association task force on clinical practice guidelines. J. Am. Coll. Cardiol. 70, 252-289. doi: 10.1016/j.jacc. 2017.03.011

Nishimura, R. A., Otto, C. M., Bonow, R. O., Carabello, B. A., Erwin, J. R. Guyton, R. A., et al. (2014). 2014 AHA/ACC guideline for the management of patients with valvular heart disease: a report of the American college of cardiology/American heart association task force on practice guidelines. Circulation 129, e521-e643. doi: 10.1161/CIR.0000000000000031

Nistri, S., Porciani, M. C., Attanasio, M., Abbate, R., Gensini, G. F., and Pepe, G. (2012). Association of Marfan syndrome and bicuspid aortic valve: frequency and outcome. Int. J. Cardiol. 155, 324-325. doi: 10.1016/j.ijcard.2011.12.009

Nucifora, G., Miller, J., Gillebert, C., Shah, R., Perry, R., Raven, C., et al. (2018). Ascending aorta and myocardial mechanics in patients with "Clinically Normal” bicuspid aortic valve. Int. Heart J. 59, 741-749. doi: 10.1536/ihj.17-230

Okita, Y. (2015). Surgery for thoracic aortic disease in Japan: evolving strategies toward the growing enemies. Gen. Thorac. Cardiovasc. Surg. 63, 185-196. doi: 10.1007/s11748-014-0476-9

Ouzounian, M., Mazine, A., and David, T. E. (2017). The Ross procedure is the best operation to treat aortic stenosis in young and middle-aged adults. J. Thorac. Cardiovasc. Surg. 154, 778-782. doi: 10.1016/j.jtcvs.2017. 03.156

Ouzounian, M., Rao, V., Manlhiot, C., Abraham, N., David, C., Feindel, C. M et al. (2016). Valve-sparing root replacement compared with composite valve graft procedures in patients with aortic root dilation. J. Am. Coll. Cardiol. 68, 1838-1847. doi: 10.1016/j.jacc.2016.07.767 
Ozaki, S., Kawase, I., Yamashita, H., Uchida, S., Nozawa, Y., Takatoh, M., et al. (2014). A total of 404 cases of aortic valve reconstruction with glutaraldehydetreated autologous pericardium. J. Thorac. Cardiovasc. Surg. 147, 301-306. doi: 10.1016/j.jtcvs.2012.11.012

Padang, R., Bagnall, R. D., Richmond, D. R., Bannon, P. G., and Semsarian, C. (2012). Rare non-synonymous variations in the transcriptional activation domains of GATA5 in bicuspid aortic valve disease. J. Mol. Cell. Cardiol. 53, 277-281. doi: 10.1016/j.yjmcc.2012.05.009

Padang, R., Gersh, B. J., Ommen, S. R., and Geske, J. B. (2018). Prevalence and impact of coexistent bicuspid aortic valve in hypertrophic cardiomyopathy. Heart Lung Circ. 27, 33-40. doi: 10.1016/j.hlc.2017.01.020

Paloschi, V., Gadin, J. R., Khan, S., Bjorck, H. M., Du, L., Maleki, S., et al. (2015). Aneurysm development in patients with a bicuspid aortic valve is not associated with transforming growth factor-beta activation. Arterioscler. Thromb. Vasc. Biol. 35, 973-980. doi: 10.1161/ATVBAHA.114.304996

Park, J. Y., Foley, T. A., Bonnichsen, C. R., Maurer, M. J., Goergen, K. M., Nkomo, V. T., et al. (2017). Transthoracic echocardiography versus computed tomography for ascending aortic measurements in patients with bicuspid aortic valve. J. Am. Soc. Echocardiogr. 30, 625-635. doi: 10.1016/j.echo.2017.03.006

Patel, P. A., Gutsche, J. T., Vernick, W. J., Giri, J. S., Ghadimi, K., Weiss, S. J., et al. (2015). The functional aortic annulus in the 3D era: focus on transcatheter aortic valve replacement for the perioperative echocardiographer. J. Cardiothorac. Vasc. Anesth. 29, 240-245. doi: 10.1053/j.jvca.2014.05.027

Perlman, G. Y., Blanke, P., Dvir, D., Pache, G., Modine, T., Barbanti, M., et al. (2016). Bicuspid aortic valve stenosis: favorable early outcomes with a nextgeneration transcatheter heart valve in a multicenter study. JACC Cardiovasc. Interv. 9, 817-824. doi: 10.1016/j.jcin.2016.01.002

Philip, F., Faza, N. N., Schoenhagen, P., Desai, M. Y., Tuzcu, E. M., Svensson, L. G., et al. (2015). Aortic annulus and root characteristics in severe aortic stenosis due to bicuspid aortic valve and tricuspid aortic valves: implications for transcatheter aortic valve therapies. Catheter. Cardiovasc. Interv. 86, E88-E98. doi: $10.1002 / \mathrm{ccd} .25948$

Phillippi, J. A., Klyachko, E. A., Kenny, J. T., Eskay, M. A., Gorman, R. C., and Gleason, T. G. (2009). Basal and oxidative stress-induced expression of metallothionein is decreased in ascending aortic aneurysms of bicuspid aortic valve patients. Circulation 119, 2498-2506. doi: 10.1161/CIRCULATIONAHA. 108.770776

Pibarot, P., and Dumesnil, J. G. (2012). Improving assessment of aortic stenosis. J. Am. Coll. Cardiol. 60, 169-180. doi: 10.1016/j.jacc.2011.11.078

Poh, C. L., Buratto, E., Larobina, M., Wynne, R., O’Keefe, M., Goldblatt, J., et al. (2018). The Ross procedure in adults presenting with bicuspid aortic valve and pure aortic regurgitation: $85 \%$ freedom from reoperation at 20 years. Eur. J. Cardiothorac. Surg. 54, 420-426. doi: 10.1093/ejcts/ezy073

Puranik, R., Tsang, V. T., Broadley, A., Nordmeyer, J., Lurz, P., Muthialu, N., et al. (2010). Functional outcomes after the Ross (pulmonary autograft) procedure assessed with magnetic resonance imaging and cardiopulmonary exercise testing. Heart 96, 304-308. doi: 10.1136/hrt.2009.172965

Reece, T. B., Welke, K. F., O'Brien, S., Grau-Sepulveda, M. V., Grover, F. L., and Gammie, J. S. (2014). Rethinking the ross procedure in adults. Ann. Thorac. Surg. 97, 175-181. doi: 10.1016/j.athoracsur.2013.07.036

Renard, M., Callewaert, B., Malfait, F., Campens, L., Sharif, S., Del, C. M., et al. (2013). Thoracic aortic-aneurysm and dissection in association with significant mitral valve disease caused by mutations in TGFB2. Int. J. Cardiol. 165, 584-587. doi: 10.1016/j.ijcard.2012.09.029

Reuthebuch, O., Koechlin, L., Schurr, U., Grapow, M., Fassl, J., and Eckstein, F. S. (2018). Aortic valve replacement using autologous pericardium: single centre experience with the Ozaki technique. Swiss Med. Wkly. 148:w14591. doi: 10.4414/smw.2018.14591

Roman, M. J., Pugh, N. L., Devereux, R. B., Eagle, K. A., Holmes, K., LeMaire, S. A., et al. (2017). Aortic dilatation associated with bicuspid aortic valve: relation to sex, hemodynamics, and valve morphology (the National Heart Lung and Blood Institute-Sponsored National Registry of Genetically Triggered Thoracic Aortic Aneurysms and Cardiovascular Conditions). Am. J. Cardiol. 120, 1171-1175. doi: 10.1016/j.amjcard.2017.06.061

Ruzmetov, M., Shah, J. J., Fortuna, R. S., and Welke, K. F. (2015). The association between aortic valve leaflet morphology and patterns of aortic dilation in patients with bicuspid aortic valves. Ann. Thorac. Surg. 99, 2101-2107; discussion 2107-2108. doi: 10.1016/j.athoracsur.2015.02.036
Sannino, A., Cedars, A., Stoler, R. C., Szerlip, M., Mack, M. J., and Grayburn, P. A. (2017). Comparison of efficacy and safety of transcatheter aortic valve implantation in patients with bicuspid versus tricuspid aortic valves. Am. J. Cardiol. 120, 1601-1606. doi: 10.1016/j.amjcard.2017.07.053

Schneider, U., Hofmann, C., Aicher, D., Takahashi, H., Miura, Y., and Schafers, H. J. (2017). Suture annuloplasty significantly improves the durability of bicuspid aortic valve repair. Ann. Thorac. Surg. 103, 504-510. doi: 10.1016/j.athoracsur. 2016.06.072

Shen, M., Tastet, L., Capoulade, R., Larose, E., Bedard, E., Arsenault, M., et al. (2017). Effect of age and aortic valve anatomy on calcification and haemodynamic severity of aortic stenosis. Heart 103, 32-39. doi: 10.1136/ heartjnl-2016-309665

Siddiqui, J., Brizard, C. P., Konstantinov, I. E., Galati, J., Wheaton, G., Cheung, M., et al. (2013). Outcomes after operations for bicuspid aortic valve disease in the pediatric population. Ann. Thorac. Surg. 96, 2175-2183. doi: 10.1016/j. athoracsur.2013.07.130

Sievers, H. H., and Schmidtke, C. (2007). A classification system for the bicuspid aortic valve from 304 surgical specimens. J. Thorac. Cardiovasc. Surg. 133, 1226-1233. doi: 10.1016/j.jtcvs.2007.01.039

Sievers, H. H., Stierle, U., Charitos, E. I., Takkenberg, J. J., Horer, J., Lange, R., et al. (2016). A multicentre evaluation of the autograft procedure for young patients undergoing aortic valve replacement: update on the German Ross Registrydagger. Eur. J. Cardiothorac. Surg. 49, 212-218. doi: 10.1093/ejcts/ ezv001

Sievers, H. H., Stierle, U., Mohamed, S. A., Hanke, T., Richardt, D., Schmidtke, C., et al. (2014). Toward individualized management of the ascending aorta in bicuspid aortic valve surgery: the role of valve phenotype in 1362 patients. J. Thorac. Cardiovasc. Surg. 148, 2072-2080. doi: 10.1016/j.jtcvs.2014.04.007

Siu, S. C., and Silversides, C. K. (2010). Bicuspid aortic valve disease. J. Am. Coll. Cardiol. 55, 2789-2800. doi: 10.1016/j.jacc.2009.12.068

Sotelo, J., Dux-Santoy, L., Guala, A., Rodriguez-Palomares, J., Evangelista, A., and Sing-Long, C. (2018). 3D axial and circumferential wall shear stress from 4D flow MRI data using a finite element method and a laplacian approach. Magn. Reson. Med. 79, 2816-2823. doi: 10.1002/mrm.26927

Spaziani, G., Ballo, P., Favilli, S., Fibbi, V., Buonincontri, L., Pollini, I., et al. (2014). Clinical outcome, valve dysfunction, and progressive aortic dilation in a pediatric population with isolated bicuspid aortic valve. Pediatr. Cardiol. 35, 803-809. doi: 10.1007/s00246-013-0856-4

Sun, B. J., Lee, S., Jang, J. Y., Kwon, O., Bae, J. S., Lee, J. H., et al. (2017). Performance of a simplified dichotomous phenotypic classification of bicuspid aortic valve to predict type of valvulopathy and combined aortopathy. J. Am. Soc. Echocardiogr. 30, 1152-1161. doi: 10.1016/j.echo.2017.08.002

Svensson, L. G., Al, K. A., Vivacqua, A., Pettersson, G. B., Gillinov, A. M., Mihaljevic, T., et al. (2014). Long-term durability of bicuspid aortic valve repair. Ann. Thorac. Surg. 97, 1539-1547; discussion 1548. doi: 10.1016/j.athoracsur. 2013.11.036

Tang, P. C., Badami, A., Akhter, S. A., Osaki, S., Lozonschi, L., Kohmoto, T., et al. (2017). Efficacy of aortic valve resuspension in establishing valve competence in acute type a dissections. Ann. Thorac. Surg. 103, 1460-1466. doi: 10.1016/j. athoracsur.2016.08.099

Thaden, J. J., Nkomo, V. T., Lee, K. J., and Oh, J. K. (2015). Doppler imaging in aortic stenosis: the importance of the nonapical imaging windows to determine severity in a contemporary cohort. J. Am. Soc. Echocardiogr. 28, 780-785. doi: 10.1016/j.echo.2015.02.016

Theodoris, C. V., Li, M., White, M. P., Liu, L., He, D., Pollard, K. S., et al. (2015). Human disease modeling reveals integrated transcriptional and epigenetic mechanisms of NOTCH1 haploinsufficiency. Cell 160, 1072-1086. doi: 10.1016/ j.cell.2015.02.035

Treibel, T. A., Lopez, B., Gonzalez, A., Menacho, K., Schofield, R. S., Ravassa, S., et al. (2018). Reappraising myocardial fibrosis in severe aortic stenosis: an invasive and non-invasive study in 133 patients. Eur. Heart J. 39, 699-709. doi: 10.1093/eurheartj/ehx353

Van Hemelrijk, C., Renard, M., and Loeys, B. (2010). The Loeys-Dietz syndrome: an update for the clinician. Curr. Opin. Cardiol. 25, 546-551. doi: 10.1097/HCO. 0b013e32833f0220

Verma, S., and Siu, S. C. (2014). Aortic dilatation in patients with bicuspid aortic valve. N. Engl. J. Med. 370, 1920-1929. doi: 10.1056/NEJMra120 7059 
von Knobelsdorff-Brenkenhoff, F., Karunaharamoorthy, A., Trauzeddel, R. F., Barker, A. J., Blaszczyk, E., Markl, M., et al. (2016). Evaluation of aortic blood flow and wall shear stress in aortic stenosis and its association with left ventricular remodeling. Circ. Cardiovasc. Imaging 9:e4038. doi: 10.1161/ CIRCIMAGING.115.004038

Wang, Y., Wang, M., Song, G., Wang, W., Lv, B., Wang, H., et al. (2018). Optimal pre-TAVR annulus sizing in patients with bicuspid aortic valve: area-derived perimeter by CT is the best-correlated measure with intraoperative sizing. Eur. Radiol. doi: 10.1007/s00330-018-5592-y [Epub ahead of print].

Wang, Y. B., Li, Y., Deng, Y. B., Liu, Y. N., Zhang, J., and Sun, J. (2018). Enlarged size and impaired elastic properties of the ascending aorta are associated with endothelial dysfunction and elevated plasma matrix metalloproteinase-2 level in patients with bicuspid aortic valve. Ultrasound Med. Biol. 44, 955-962. doi: 10.1016/j.ultrasmedbio.2018.01.012

Wang, Y., Wu, B., Dong, L., Wang, C., Wang, X., and Shu, X. (2016). Circulating matrix metalloproteinase patterns in association with aortic dilatation in bicuspid aortic valve patients with isolated severe aortic stenosis. Heart Vessels 31, 189-197. doi: 10.1007/s00380-014-0593-5

Ward, R. M., Marsh, J. M., Gossett, J. M., Rettiganti, M. R., and Collins, R. N. (2018). Impact of bicuspid aortic valve morphology on aortic valve disease and aortic dilation in pediatric patients. Pediatr. Cardiol. 39, 509-517. doi: 10.1007/s00246-017-1781-8

Weismann, C. G., Lombardi, K. C., Grell, B. S., Northrup, V., and Sugeng, L. (2016). Aortic stiffness and left ventricular diastolic function in children with well-functioning bicuspid aortic valves. Eur. Heart J. Cardiovasc. Imaging 17, 225-230. doi: 10.1093/ehjci/jev151

Wojnarski, C. M., Svensson, L. G., Roselli, E. E., Idrees, J. J., Lowry, A. M., Ehrlinger, J., et al. (2015). Aortic dissection in patients with bicuspid aortic valve-associated aneurysms. Ann. Thorac. Surg. 100, 1666-1673; discussion 1673-1674. doi: 10.1016/j.athoracsur.2015.04.126

Wu, J., Song, H. F., Li, S. H., Guo, J., Tsang, K., Tumiati, L., et al. (2016). Progressive aortic dilation is regulated by miR-17-associated miRNAs. J. Am. Coll. Cardiol. 67, 2965-2977. doi: 10.1016/j.jacc.2016.04.027

Xu, Y. N., Xiong, T. Y., Li, Y. J., Liao, Y. B., Zhao, Z. G., Wei, X., et al. (2018). Balloon sizing during transcatheter aortic valve implantation: comparison of different valve morphologies. Herz doi: 10.1007/s00059-018-4714-2 [Epub ahead of print].

Xuan, Y., Wang, Z., Liu, R., Haraldsson, H., Hope, M. D., Saloner, D. A., et al. (2018). Wall stress on ascending thoracic aortic aneurysms with bicuspid compared with tricuspid aortic valve. J. Thorac. Cardiovasc. Surg. 156, 492-500. doi: 10.1016/j.jtcvs.2018.03.004

Yakar, T. S., Tuluce, K., Simsek, E. C., Safak, O., Okten, M. S., Yapan, E. Z., et al. (2017). Assessment of bicuspid aortic valve phenotypes and associated pathologies: a transesophageal echocardiographic study. Turk Kardiyol. Dern. Ars. 45, 690-701. doi: 10.5543/tkda.2017.03152

Yamashita, T., Hayashi, T., Tabata, T., and Hirata, K. I. (2018). Bicuspid aortic valve-associated aortic dilatation- what is the mechanism of bicuspid aortopathy? Circ. J. 82, 2470-2471. doi: 10.1253/circj.CJ-18-0844

Yang, B., Zhou, W., Jiao, J., Nielsen, J. B., Mathis, M. R., Heydarpour, M., et al. (2017). Protein-altering and regulatory genetic variants near GATA4 implicated in bicuspid aortic valve. Nat. Commun. 8:15481. doi: 10.1038/ncomms15481
Yang, T. H., Webb, J. G., Blanke, P., Dvir, D., Hansson, N. C., Norgaard, B. L., et al. (2015). Incidence and severity of paravalvular aortic regurgitation with multidetector computed tomography nominal area oversizing or undersizing after transcatheter heart valve replacement with the Sapien 3: a comparison with the Sapien XT. JACC Cardiovasc. Interv. 8, 462-471. doi: 10.1016/j.jcin.2014.10. 014

Yassine, N. M., Shahram, J. T., and Body, S. C. (2017). Pathogenic mechanisms of bicuspid aortic valve aortopathy. Front. Physiol. 8:687. doi: 10.3389/fphys.2017. 00687

Yoon, S. H., Bleiziffer, S., De Backer, O., Delgado, V., Arai, T., Ziegelmueller, J., et al. (2017). Outcomes in transcatheter aortic valve replacement for bicuspid versus tricuspid aortic valve stenosis. J. Am. Coll. Cardiol. 69, 2579-2589. doi: 10.1016/j.jacc.2017.03.017

Yoon, S. H., Lefevre, T., Ahn, J. M., Perlman, G. Y., Dvir, D., Latib, A., et al. (2016). Transcatheter aortic valve replacement with early- and new-generation devices in bicuspid aortic valve stenosis. J. Am. Coll. Cardiol. 68, 1195-1205. doi: 10.1016/j.jacc.2016.06.041

Youssefi, P., Sharma, R., Figueroa, C. A., and Jahangiri, M. (2017). Functional assessment of thoracic aortic aneurysms - the future of risk prediction? Br. Med. Bull. 121, 61-71. doi: 10.1093/bmb/ldw049

Zacek, P., Holubec, T., Vobornik, M., Dominik, J., Takkenberg, J., Harrer, J., et al. (2016). Quality of life after aortic valve repair is similar to Ross patients and superior to mechanical valve replacement: a cross-sectional study. BMC Cardiovasc. Disord. 16:63. doi: 10.1186/s12872-016-0236-0

Zeeshan, A., Idrees, J. J., Johnston, D. R., Rajeswaran, J., Roselli, E. E., Soltesz, E. G., et al. (2018). Durability of aortic valve cusp repair with and without annular support. Ann. Thorac. Surg. 105, 739-748. doi: 10.1016/j.athoracsur.2017.09. 019

Zegdi, R., Ciobotaru, V., Noghin, M., Sleilaty, G., Lafont, A., Latremouille, C., et al. (2008). Is it reasonable to treat all calcified stenotic aortic valves with a valved stent? Results from a human anatomic study in adults. J. Am. Coll. Cardiol. 51, 579-584. doi: 10.1016/j.jacc.2007.10.023

Zegri-Reiriz, I., de Alarcon, A., Munoz, P., Martinez, S. M., Gonzalez-Ramallo, V., Miro, J. M., et al. (2018). Infective endocarditis in patients with bicuspid aortic valve or mitral valve prolapse. J. Am. Coll. Cardiol. 71, 2731-2740. doi: 10.1016/ j.jacc.2018.03.534

Zhao, Z. G., Jilaihawi, H., Feng, Y., and Chen, M. (2015). Transcatheter aortic valve implantation in bicuspid anatomy. Nat. Rev. Cardiol. 12, 123-128. doi: $10.1038 /$ nrcardio. 2014.161

Conflict of Interest Statement: The authors declare that the research was conducted in the absence of any commercial or financial relationships that could be construed as a potential conflict of interest.

Copyright (C) 2019 Liu, Xie, Lv, Li, Fang, Zhang, Deng and Wang. This is an openaccess article distributed under the terms of the Creative Commons Attribution License (CC BY). The use, distribution or reproduction in other forums is permitted, provided the original author(s) and the copyright owner(s) are credited and that the original publication in this journal is cited, in accordance with accepted academic practice. No use, distribution or reproduction is permitted which does not comply with these terms. 